\title{
Neuroblast Long-Term Cell Cultures from Human Fetal Olfactory Epithelium Respond to Odors
}

\author{
Gabriella B. Vannelli, ${ }^{1}$ Fabrizio Ensoli, ${ }^{7}$ Roberto Zonefrati,, ${ }^{2}$ Yoshi-hisa Kubota, ${ }^{6}$ Annarosa Arcangeli, ${ }^{3}$ Andrea \\ Becchetti, ${ }^{5}$ Guido Camici, ${ }^{4}$ Tullio Barni, ${ }^{1}$ Carol J. Thiele, ${ }^{7}$ and Giuseppe C. Balboni ${ }^{1}$ \\ ${ }^{1}$ Department of Human Anatomy and Histology, ${ }^{2} \mathrm{Clinica}$ Medica III, 3 Institute of General Pathology, ${ }^{4}$ Institute of \\ Biochemistry, University of Florence, Italy, ${ }^{5}$ Department of General Physiology and Biochemistry, University of \\ Milan, Italy, ${ }^{6}$ Department of Molecular and Cell Biology, University of California, Berkeley, California, and ${ }^{7}$ Cellular \\ and Molecular Biology Section, Pediatric Branch, $\mathrm{NCl}, \mathrm{NIH}$, Bethesda, Maryland
}

\begin{abstract}
Primary cell cultures from human fetal olfactory neuroepithelium have been isolated, cloned, and propagated in continuous in vitro culture for approximately 1 year. The two clones we report here synthesize both neuronal proteins and olfactory-specific markers as well as the putative olfactory neurotransmitter, carnosine. In addition, patchclamp experiments reveal that these cells are electrically excitable. Following exposure to a panel of aromatic chemicals one of the cell cultures shows a specific increase in intracellular cAMP, indicating that some degree of functional maturity is expressed in vitro. The results suggest that these cells originate from the "stem cell" compartment that gives rise to mature olfactory receptor neurons. These long-term cell cultures represent models that will be useful in studying the mechanism(s) of olfaction and the regulation of olfactory neurogenesis and differentiation.
\end{abstract}

[Key words: primary cultures, neuroblasts, stem cells, olfactory neurogenesis, odorants, cAMP]

Olfactory primary sensory neurons (ORN) are located in a pseudostratified columnar epithelium of the upper nasal cavity. Their unmyelinated axons penetrate the basal lamina, enter the cranium via foramina in the cribriform plate and synapse in the olfactory bulb of the CNS. During development, olfactory neuronal precursors divide, migrate, and differentiate, establishing

\footnotetext{
Received June 21, 1994; revised Jan. 6, 1995; accepted Jan. 13, 1995.

We gratefully acknowledge Dr. Frank L. Margolis (Laboratory of Chemosensory Neurobiology, Roche Institute of Molecular Biology), Drs. Donald F. Steiner, and Jeffrey M. Zigman (Department of Biochemistry and Molecular Biology, Howard Hughes Medical Institute, University of Chicago), and Dr. Randall R. Reed (Howard Hughes Medical Institute, Department of Molecular Biology and Genetics, Johns Hopkins University School of Medicine) for generously providing their cDNA clones. We also thank Prof. Alessandro Riva, Department of Cytomorphology, University of Cagliari, for supervision of ultrastructural studies; Prof. Roberto Toccafondi, Clinica Medica III, University of Florence, for the assistance with cell cultures; Dr. Francesca Torricelli, Department of Cytogenetics, University of Florence, for help with karyotype analysis; and Dr. Daniele Prucher and Giotti Industria Essenze, Florence, for their kind assistance. Finally, we are grateful to Prof. Gianpiero Marconi, Department of Neurological and Psychiatric Sciences, University of Florence, for critically reviewing the manuscript. This work was supported by grants from the Ministero della Universitá Ricerca Scientifica e Tecnologica (MURST), Associazione Italiana per la Ricerca sul Cancro (AIRC), Associazione Italiana Sclerosi Laterale Amiotrofica (AISLA, Florence), and from Consiglio Nazionale delle Ricerche (CNR ACRO 94.01176.PF39; 94.02933.CT04).

Correspondence should be addressed to Gabriella B. Vannelli, Department of Human Anatomy and Histology, University of Florence, Viale Morgagni 85 , 50134 Florence, Italy.

Copyright $(1995$ Society for Neuroscience $\quad 0270-6474 / 95 / 154382-13 \$ 05.00 / 0$
}

central and peripheral connections responsible for transmitting chemosensory information to the brain (Graziadei and MontiGraziadei, 1979). Olfactory neurogenesis is both spatially and temporally regulated, continues throughout life, and is essential to maintain the sensory capacity of the olfactory system (Graziadei, 1973; Graziadei and Monti-Graziadei, 1978). The notion that olfactory sensory neurons are renewed fron a population of dividing stem cells suggests the possibility to propagate olfactory neuronal precursors in vitro.

Primary cultures from rat olfactory neuroepithelium gave rise to differentiated olfactory neurons in vitro (Calof et al., 1989; Pixley et al., 1990; Chuah et al., 1991; Ronnett et al., 1991) and cells from olfactory epithelium of newborn rats, expressing both neuronal and olfactory properties have been successfully cloned (Coon et al., 1989). Recently, cells exhibiting characteristics of olfactory neurons have been obtained from explants of adult human olfactory epithelium (Wolozin et al., 1992). These cells expressed both neuronal and epithelial markers, molecules specific to the olfactory system and odorant-dependent cAMP accumulation (Wolozin et al., 1992). However, they had a finite life span. The growth rate and the number of possible passages in culture varied inversely with the age of the donor, increasing with cells obtained from younger adults (Wolozin et al., 1992). The availability of olfactory neuroblasts from humans may represent a valuable tool with which to study mechanisms regulating the olfactory response, as well as the process of olfactory neurogenesis and differentiation.

In this study we describe two cloned cell cultures obtained from the human fetal olfactory neuroepithelium that have been continuously cultured for about 1 year. Although histologically they appear to be incompletely differentiated, they show biochemical and antigenic properties of olfactory neurons. One of them is selectively and sensitively responsive to odorant stimuli.

\section{Materials and Methods}

Preparation of cell cultures from human fetal olfactory epithelium

Six human fetuses at different gestational ages (8-12 weeks) were dissected 3-5 hr after spontaneous or therapeutic abortion. (Legal abortion were performed in authorized hospitals and certificates of approval were obtained from patients. The study protocols were approved by the University Ethical Committee.) Fertilization ages were confirmed according to the crown-rump length. "Heminoses" were obtained by sagittal bisection of fetal heads and removed under sterile conditions. Six heminoses were fixed in Bouin's solution, or fixed and stained by zinc iodide/ osmium tetroxide solution (ZIO) 3:1 (Maillet, 1959), embedded in par- 
affin and used for morphological detail (Fig. 1A). The mucosa lining the upper nasal cavity and septum was removed from the remaining six heminoses and cut into $0.5-1 \mathrm{~mm}$ pieces. Tissue fragments were washed with phosphate-buffered saline (PBS) pH 7.4 and enzymatically digested by two successive incubations $\left(1\right.$ and $2 \mathrm{hr}$, respectively, at $37^{\circ} \mathrm{C}$ in humidified $5 \% \mathrm{CO}_{2}$ atmosphere) in Coon's modified Ham's F12 medium supplemented with $0.5 \mathrm{mg} / \mathrm{ml}$ of crude collagenase (Worthington Bio. Co., Freehold, NJ) and 5\% adult calf serum. Digested tissues were mechanically dispersed by pipetting and cell suspensions were washed with $\mathrm{Ca}^{2+} / \mathrm{Mg}^{2+}$-free PBS. Erythrocytes and debris were removed by centrifugation $(10 \mathrm{~min}$ at $750 \times \mathrm{g})$ on a discontinuous gradient consisting of $25 \%$ dialyzed Ficoll solution (Pharmacia, Uppsala, Sweden) in Coon's modified Ham's F12 medium.

Dissociated cells from olfactory mucosa were resuspended in Coon's modified Ham's F12 medium supplemented with $10 \%$ fetal calf serum (FCS). Approximately $5 \times 10^{5}$ cells $/ \mathrm{cm}^{2}$ were seeded in $60 \mathrm{~mm}$ plastic tissue culture dishes (COSTAR) and cultured at $37^{\circ} \mathrm{C}$ in $5 \% \mathrm{CO}_{2}$ atmosphere.

Primary cell cultures were fed with fresh medium twice weekly. After two to three passages, single cell suspensions were plated for cloning at limiting dilution in 96 wells, half-area plates. Clones were fed by a "cloning medium" consisting of 1:1 mixture of Coon's modified Hams's F12 medium and the same medium conditioned by incubation for $24 \mathrm{hr}$ with the "parental" primary cell cultures, plus $10 \%$ FCS. After 3-4 weeks, colonies were selectively trypsinized and transferred to individual $60 \mathrm{~mm}$ dishes. Two of these clones, named FNC-A6 and FNC-B4, are described in the present study.

Antisera. The following polyclonal (PA) or monoclonal (MA) antibodies were used for immunocytochemical or immunoblot analysis at the indicated dilutions: rabbit PA to human neuron-specific enolase (NSE) (Polysciences, Warrington, PA) dilution 1:1000. Mouse MA to human Vimentin (Vm), clone V9, dilution 1:50 (Dakopatts, Copenhagen, Denmark). Mouse MA to human Neurofilament 200 (NF), clone N52, dilution 1:200; mouse MA to rat neural cell adhesion molecule (N-CAM), clone NCAM-OB11, dilution 1:100 (Sigma, St.Louis, MO). Mouse MA to human cytokeratin, clone Lu-5, dilution 1:10 (Boehringer-Mannheim). Goat PA to rat olfactory marker protein (OMP), used at dilution 1:500, was a generous gift of Dr. Frank Margolis, Roche Institute, Nutley, NJ.

Immunocytochemical procedures. Indirect immunofluorescence technique was used for immunocytochemical staining. Briefly, after growing the cells on sterile slides, cultures were washed twice with PBS pH 7.4 and fixed in $3.7 \%$ paraformaldehyde in PBS for $15 \mathrm{~min}$ at room temperature (RT), followed by permeabilization in $3.7 \%$ paraformaldehydePBS containing $0.1 \%$ Triton X-100 for $15 \mathrm{~min}$ at RT. Alternatively, some slides were dried overnight and fixed for $10 \mathrm{~min}$ in cold acetone.

Primary antibodies, appropriately diluted in PBS containing $2 \%$ Bovine Serum Albumin (BSA), were added to the slides and incubated overnight at $4^{\circ} \mathrm{C}$. Slides were washed three times ( 5 min each) in PBS and incubated at RT for $45 \mathrm{~min}$ with PBS-2\% BSA containing the fluoresceinated second antibodies at the appropriate dilution (goat antirabbit, 1:80 to 1:300; goat anti-mouse, 1:100; rabbit anti-goat, 1:100) (Sigma, St Louis, MO). After washing (three times in PBS) slides were examined with a phase contrast microscope equipped with epifluorescence (Nikon microphot-FX microscope; Nikon, Kogaku, Tokyo, Japan). Controls were performed by processing slides lacking the primary antibodies or stained with the corresponding nonimmune serum.

Immunoblot. Western blotting was performed as previously described (Coon et al., 1989). Briefly, cell cultures or control rat tissues were sonicated for $20 \mathrm{sec}$ in $10 \mathrm{~mm}$ sodium phosphate buffer $\mathrm{pH} 7.5,100$ mм NaCl, 1 mм EDTA, $1 \%$ Triton X-100, $0.5 \%$ sodium deoxycholate, $0.1 \% \mathrm{NaDodSO}_{4}, 50 \mu \mathrm{g}$ of phenylmethanesulfonyl fluoride per ml, 10 $\mu \mathrm{g} / \mathrm{ml}$ L-1-tosylamido-2-phenylethyl chloromethyl ketone, $1 \mu \mathrm{g} / \mathrm{ml}$ aprotinin, and $1 \mu \mathrm{g} / \mathrm{ml}$ leupeptin (Sigma). Following centrifugation $(16,000 \times g$ for $10 \mathrm{~min})$, protein concentrations were determined by bicinchoninic acid assay (Pierce).

Protein extracts were electrophoresed under denaturing condition (SDS-PAGE) on $12 \%$ (for OMP detection) or $7 \%$ (for N-CAM detection) polyacrylamide gels and electroblotted $(100 \mathrm{~V})$ to nitrocellulose filters in $20 \mathrm{~mm}$ Tris, $150 \mathrm{~mm}$ glycine, and $20 \%$ methanol for $1 \mathrm{hr}$ at $4^{\circ} \mathrm{C}$. Filters were blocked overnight with PBS containing 5\% BSA and $0.1 \%$ Tween-20 and incubated with the appropriately diluted primary antibodies for two hours at RT with gentle shaking. After washing (3 $\times 15 \mathrm{~min}$ in $0.1 \%$ tween 20 in PBS pH 7.4), filters were incubated for $90 \mathrm{~min}$ at RT with second antibodies in PBS containing 5\% BSA
A

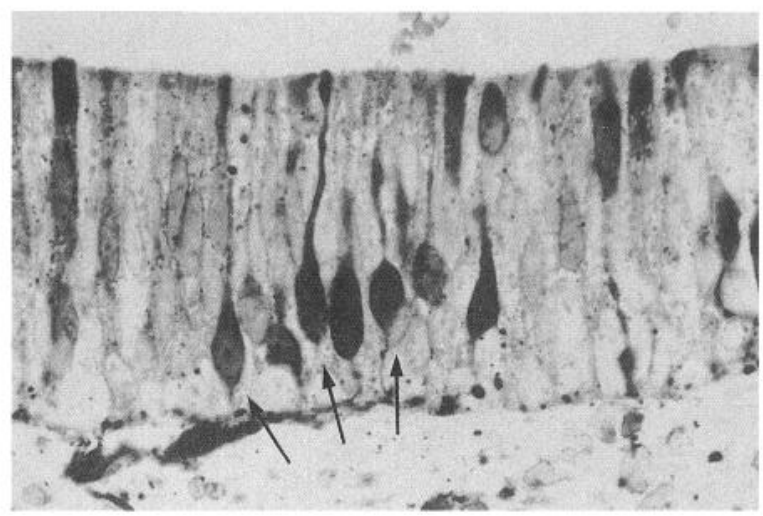

B

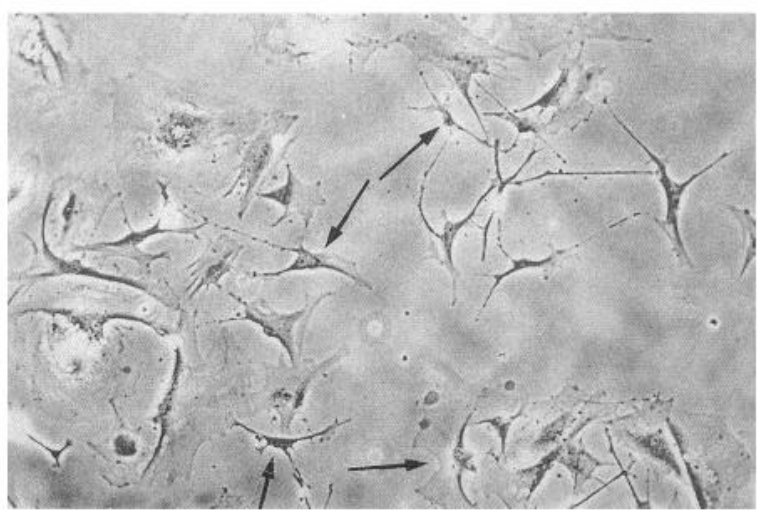

Figure 1. Cell cultures from the human fetal olfactory epithelium. Olfactory tissue and cultures were prepared as described in Materials and Methods. $A$ shows morphological details of the human (11 weeks) fetal olfactory mucosa from which the FNC-A6 cell culture was derived ( $400 \times$ magnification). Olfactory receptor neurons, stained by zinc iodide/osmium tetroxide (ZIO) technique (Maillet, 1959), appear as dark cells (arrows). They extend an apical dendritic process through the luminal sustentacular cell layer. Their axons penetrate the basal cell layer to synapse in the olfactory bulb of the CNS. $B$ shows the FNC-A6 cells (phase contrast, $200 \times$ magnification) cultured in Coon's modified Ham/ F12 medium containing 10\% FCS. Clones were selected from dissociated primary cultures as described in Materials and Methods. The culture shows varying morphologies with numerous cells extending cytoplasmic processes. Arrows indicate more typical bipolar cells.

and $0.1 \%$ Tween-20. Second antibodies were horseradish peroxidaseconjugated rabbit anti-goat (for OMP detection) or goat anti-mouse (for N-CAM detection) both diluted 1:1000 in the above buffer. Following washing $(3 \times 15 \mathrm{~min}$ in $0.1 \%$ Tween 20 in PBS pH 7.4) the specific proteins were detected by HRP color development reagent (Bio-Rad Laboratories Inc., Richmond, CA) or by enhanced chemiluminescence (ECL) kit (Amersham, UK) after exposing the filters 2 $\min$ at RT.

Northern blot. Total or polyA ${ }^{+}$RNA was isolated from each cell line or from Fischer 344 rat olfactory epithelium by either micro RNA isolation kit (Stratagene) or by Micro-FastTrak mRNA isolation kit (Invitrogen). Samples (2.5-10 $\mu \mathrm{g}$ each) were electrophoresed in $1.2 \%$ agarose/formaldehyde gel and blotted onto Hybond N (Amersham). For OMP detection, filters were hybridized $(5 \times$ SSPE, $5 \times$ Denhardt's solution, $0.5 \%$ SDS, $20 \mu \mathrm{g} / \mathrm{ml}$ sonicated salmon sperm DNA) at $65^{\circ} \mathrm{C}$ for 
A

NSE

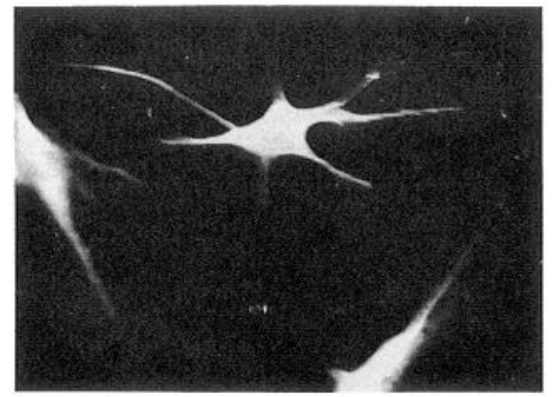

NF

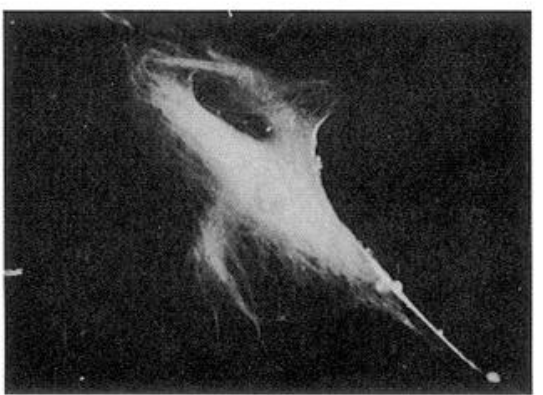

B

Figure 2. Immunophenotyping of long-term cell cultures from the human fetal olfactory neuroepithelium. Immunocytochemistry was performed as described in Materials and Methods with both FNC-A6 and FNC-B4 cell cultures. $A-C$ show FNC-A6 cells stained with antisera to neuron specific enolase (NSE), neurofilaments $(N F)$, vimentin $(\mathrm{Vm})$, cytokeratin $(\mathrm{CK})$, olfactory marker protein $(O M P)$, and neural cell adhesion molecule ( $N-C A M)$, respectively. Controls $(C)$ were performed as described in Materials and Methods. Anti-NSE gives a bright, diffuse pattern of staining, while NF defines fine cytoplasmic structures, progressively intensifying in the proximal region of emerging cellular processes. Anti- $\mathrm{Vm}$ monoclonal shows mostly perinuclear distribution. Anti-CK does not give any consistent staining. AntiOMP gives a bright, mostly cytoplasmic, staining of the cell bodies while $\mathrm{N}-\mathrm{CAM}$ defines thin cytoplasmic processes.
$\mathrm{Vm}$

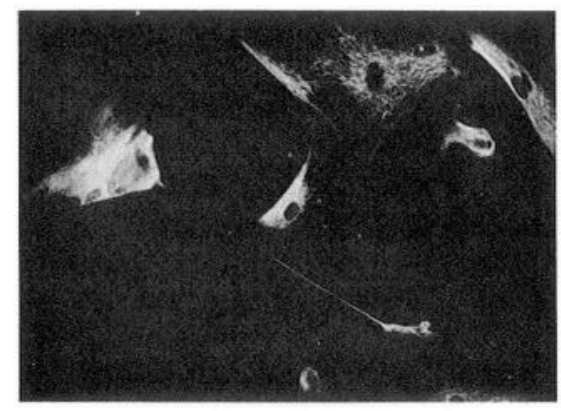

CK

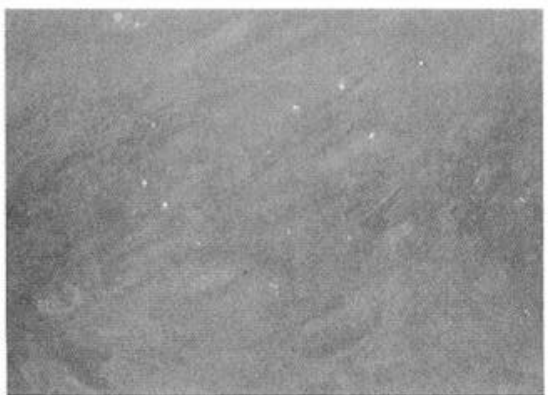

C

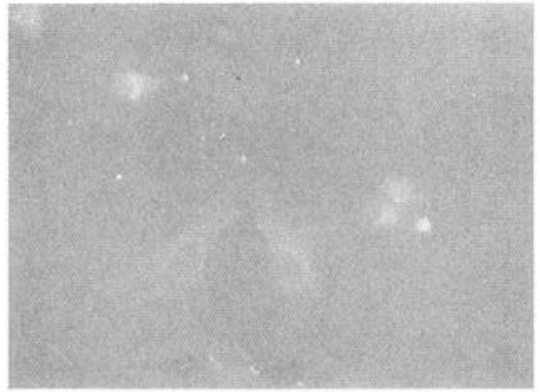

C

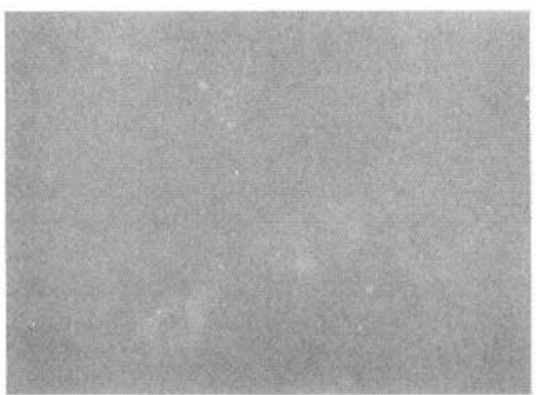

C

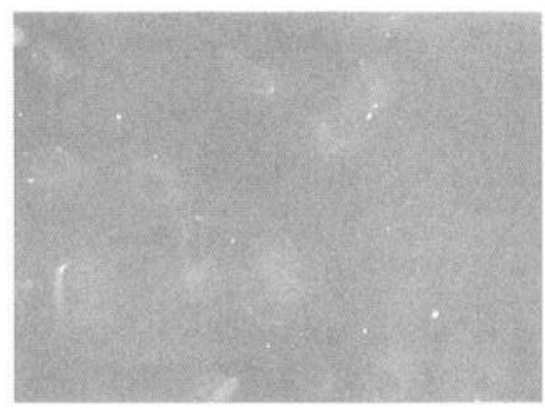

C

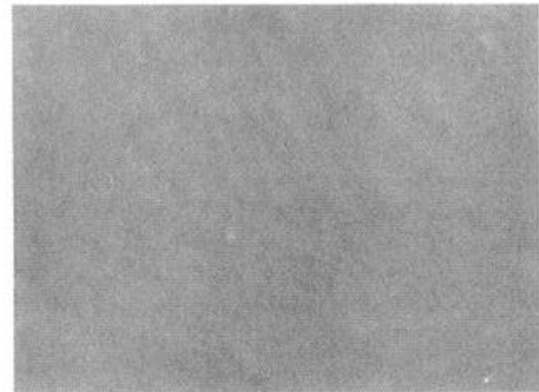

$18 \mathrm{hr}$ and washed three times $(2 \times$ SSPE, $0.1 \%$ SDS at RT for $10 \mathrm{~min}$; $1 \times$ SSPE, $0.1 \%$ SDS at $65^{\circ} \mathrm{C}$ for $15 \mathrm{~min} ; 0.1 \times$ SSPE, $0.1 \%$ SDS at $65^{\circ} \mathrm{C}$ for $15 \mathrm{~min}$ ). For other genes, hybridization was performed at $50^{\circ} \mathrm{C}$ in Rapid-Hyb buffer (Amersham Life Science) with final wash $0.5 \mathrm{X}$ $\mathrm{SSC}, 0.1 \% \mathrm{SDS}$ at $50^{\circ} \mathrm{C}$. Human OMP probe is a SalI-EcoRI fragment of human OMP gene ORF 275 bp clone in pSPORT1 (Bulakova et al., 1994). Rat olfactory cyclic nucleotide-activated channel (OCNCl) probe is a $3.0 \mathrm{~kb}$ EcoRI-BglI fragment of a cDNA clone in Bluescript II KS (Dhallan et al., 1990). Olf-1 probe is a SalI-NotI fragment of a cDNA clone in Bluescript II KS (Wang and Reed, 1993); 25-100 ng 
C

OMP

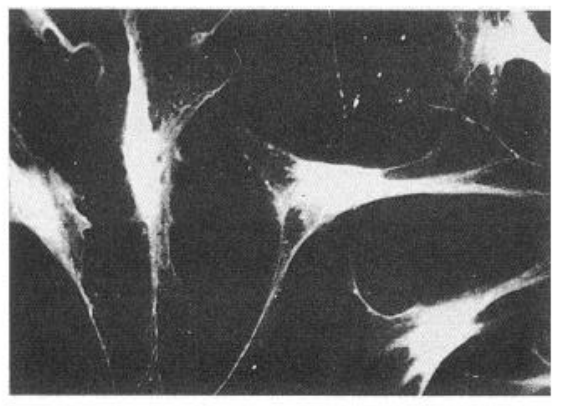

N-CAM

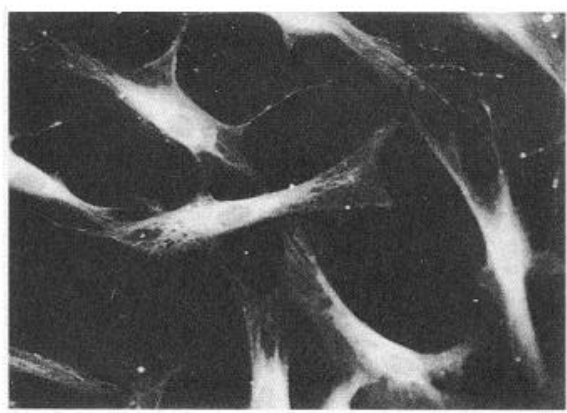

C

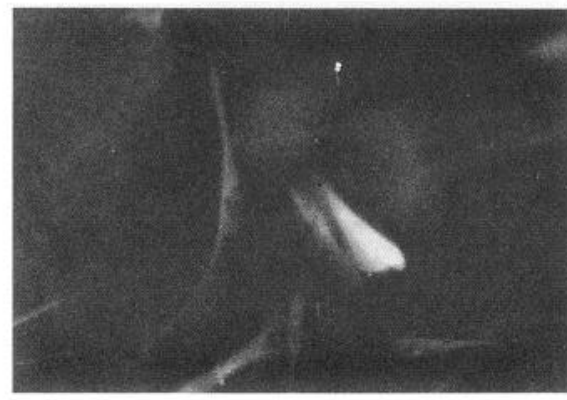

C

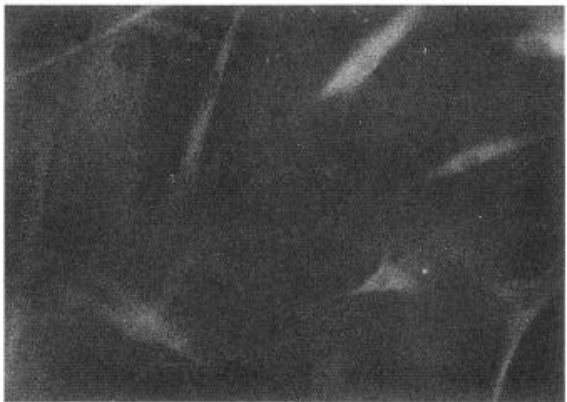

Figure 2. Continued.

of each probe were ${ }^{32} \mathrm{P}$-labeled by Megaprime DNA labeling system (Amersham)

Reverse transcription-polymerase chain reaction ( $R T-P C R)$. cDNA was obtained by random-primed reverse transcription of $1 \mu \mathrm{g}$ of RNasefree DNase I-treated polyA ${ }^{+}$RNA from both FNC-A6 and FNC-B4 cells (cDNA cycle kit, Invitrogen). To identify human $\mathrm{G}_{001} \alpha, \mathrm{PCR}$ was performed using G60/G61 primer pair as previously described (Zigman et al., 1993); $10 \mathrm{ng}$ of human $\mathrm{G}_{\text {oir }} \alpha$ cDNA (N43, Ibid.) were used as positive control.

Southern blot. $30 \%$ of the amplified product was electrophoresed in $1 \%$ agarose gel, transferred onto Hybond $\mathrm{N}$ filters (Amersham), and hybridized at high stringency conditions with an internal oligonucleotide probe (5'-ACA CTG CAG CAG AAT CTC TCC GGG) as previously described (Zigman et al., 1993).

\section{Electron microscopy}

Transmission electron microscopy. Cell pellets, obtained by centrifugation at $800 \times g$ for $5 \mathrm{~min}$, were fixed in $2.5 \%$ glutaraldehyde, $0.1 \%$ paraformaldehyde in $0.1 \mathrm{M}$ cacodylate buffer $\mathrm{pH} 7.4$ at RT for $1 \mathrm{hr}$ and postfixed with $1 \%$ osmium-tetroxide in the above buffer for $1 \mathrm{hr}$. After dehydration, cell pellets were embedded in Epon 812 (Fluka, CH-9470 Buchs, Switzerland). Ultrathin sections were stained with uranyl-acetate

\section{Table 1. Immunostaining of the FNC-A6 and FNC-B4 cell lines} by antibodies directed to neuronal and non-neuronal markers

\begin{tabular}{lcc} 
& FNC-A6 & FNC-B4 \\
\hline NSE & $>90 \%$ & $>90 \%$ \\
Vm & $60-70 \%$ & $60-70 \%$ \\
NF & $40-50 \%$ & $20-30 \%$ \\
CK & $<1 \%$ & $<1 \%$
\end{tabular}

Immunocytochemistry was performed as described in Materials and Methods. Five hundred cells were counted in each experiment, and results, normalized to the background staining, are expressed as percentage of positively stained cells. NSE, neuron-specific enolase; Vm, vimentin; NF, neurofilament; CK, cytokeratin. followed by lead citrate and examined with a Phillips 410 electron microscope.

Scanning electron microscopy. Cells were grown on sterile glass coverslips for $36 \mathrm{hr}$ and subsequently fixed with $1.5 \%$ glutaraldehyde in $0.1 \%$ M cacodylate buffer at RT for 24-36 hr. After rinsing in the same buffer, samples were dehydrated with progressive acetone dilutions and subjected to critical point drying with $\mathrm{CO}_{2}$. Cells were then coated with gold-palladium in a 5001 "cool" Polaron sputtering apparatus, mounted on stubs, and observed with Hitachi S 4000 F.E. scanning electron microscope operated at $15-20 \mathrm{Kv}$.

\section{Carnosine synthesis and extracellular release}

Cells were plated in $60 \mathrm{~mm}$ plastic dishes in Coon's modified Ham's F 12 medium. Twenty-four hours later media were removed and replaced with fresh medium containing ${ }^{3} \mathrm{H}-\beta$-Alanine $(3 \mu \mathrm{Ci} / \mathrm{ml})$ (New England Nuclear/Du Pont, Boston, MA) or medium alone. After 24, 48, and 96 $\mathrm{hr}$, media were collected, cells harvested and viability evaluated by trypan blue exclusion test.

Cell culture media and cell extracts were deproteinized with $2 \%$ sulfosalicylic acid. Carnosine was separated by high performance cationexchange chromatography (Carlo Erba 3A29 amino acid analyzer) with a lithium citrate buffer system and a physiological compound separation program. In our experimental conditions, $\beta$-alanine and carnosine were eluted at 108 and $174 \mathrm{~min}$, respectively. Fractions of $1.8 \mathrm{ml}$ were automatically collected and radioactivity assessed by liquid scintillation counting (Beckman).

\section{Electrophysiological recordings}

Sodium currents were recorded under the voltage clamp configuration of the whole-cell patch-clamp technique (Hamill et al., 1981). Patchclamp recordings were made at RT using an Axopatch-1 amplifier (Axon Instruments), 15-45 min after plating, before the cells adhere to substratum. Glass pipettes (borosilicate, Hilgenberg, Germany) (tip resistance 2-5 M $\Omega$ ) were filled with internal solution (140 mM K-aspartate, $10 \mathrm{~mm} \mathrm{NaCl}, 2 \mathrm{nM} \mathrm{MgCl}, 10 \mathrm{~mm}$ HEPES) buffered at $\mathrm{pH} 7.35$. The final $\mathrm{Ca}^{2+}$ concentration was adjusted to $10^{-7} \mathrm{M}$ by adding $4 \mathrm{~mm}$ $\mathrm{CaCl}_{2}$ and $10 \mathrm{~mm}$ EGTA. Extracellular solutions (140 mM NaCl, $3 \mathrm{~mm}$ $\mathrm{KCl}, 2 \mathrm{~mm} \mathrm{CaCl}$, $2 \mathrm{mM} \mathrm{MgCl}_{2}, 5 \mathrm{~mm}$ glucose, $10 \mathrm{~mm}$ HEPES), buffered at $\mathrm{pH} 7.4$, were delivered with hypodermic needles inserted into 


\section{OMP}

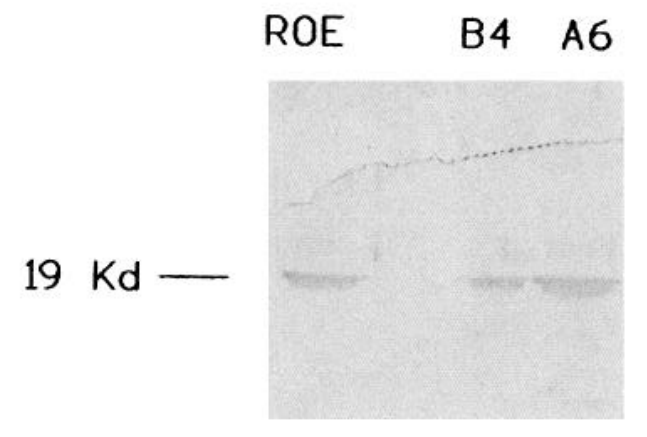

N-CAM

C4 C6 B4 A6

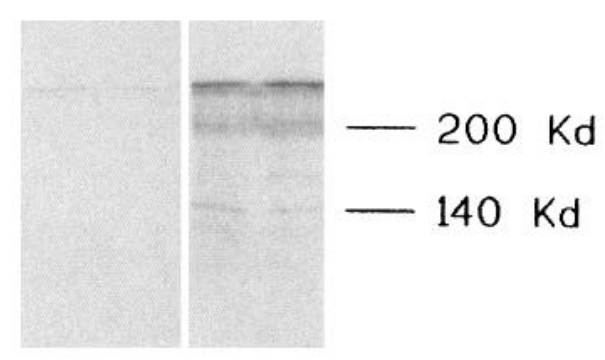

Figure 3. Western blot analysis of FNC-A6 and FNC-B4 protein extract stained with antisera to OMP or monoclonal Ab anti-N-CAM. FNC-B4 $(B 4)$ and FNC-A6 (A6) express a $19 \mathrm{kDa}$ protein positively stained by anti-OMP antisera diluted 1:500. Control was rat olfactory epithelium (ROE). Both the embryonic $(200 \mathrm{kDa})$ and the mature $(140 \mathrm{kDa})$ forms of N-CAM were detected in FNC-A6 (A6) and FNC-B4 (B4) cells by the monoclonal anti-N-CAM used at 1:100 dilution. As breakdown products of N-CAM may be stained by this antibody, they appear as multiple bands on the immunoblot. Controls (C4 and C6: FNC-B4 and FNC-A6, respectively) were performed by processing samples lacking the primary antibody.

capillaries (internal diameter $0.4 \mathrm{~mm}$ ) positioned near the cell. Tetrodotoxin (TTX, Sigma) was added at $2 \mu \mathrm{M}$ final concentration.

Electronic compensation was used to reduce the effective series resistance and the time constant of membrane charging. To avoid spaceclamp artifacts, spherical cell were always chosen (Armstrong et al., 1974; Hamill et al., 1981). Traces were corrected by analog and digital P/4 technique subtraction (Armstrong et al., 1974; Hamill et al., 1981). Voltage commands were applied and measurements of currents were made using the pCLAMP hardware and software (Axon Instruments).

\section{Determination of intracellular cAMP levels after exposure to odorants}

Cells were plated in 24 well plates (16 mm diameter) and grown to subconfluence in Coon's modified Ham's F12 plus 10\% FCS. After removing the medium, cells were washed with PBS and incubated for $30 \mathrm{~min}$ at $37^{\circ} \mathrm{C}$ in assay buffer $(0.025 \mathrm{M}$ Tris-acetate, $0.25 \mathrm{M}$ sucrose, $0.5 \%$ BSA, $5 \mathrm{~mm}$ glucose, $0.6 \mathrm{~mm}$ 3-isobutyl-1-methylxanthine) con- taining odorants or other stimulants or the solvents in which the stimulants were resuspended. To stop the reaction, equal volumes of cold $\left(-20^{\circ} \mathrm{C}\right)$ absolute ethanol were added to the cells and samples stored at $-20^{\circ} \mathrm{C}$ overnight.

After vacuum drying samples were reconstituted with $0.05 \mathrm{M}$ sodium acetate $\mathrm{pH}$ 6.2. and cAMP content determined by radioimmunoassay as previously described (Labarca et al., 1980). Results were calculated as cAMP pmol $/ \mu \mathrm{g}$ of DNA and expressed as the percentage stimulation over the basal level. Mathematical analysis was performed according to De Lean et al. (1978) by the ALLFIT software.

\section{Stimulants}

Simple odorant compounds previously studied in vitro (Shirley et al., 1986; Sklar et al., 1986; Coon et al., 1989; Ronnet et al., 1993) or commonly tested in vivo (Cain and Gent, 1986) were used (Aldrich Chimica, Milano, Italy). Other cAMP stimulants were adrenalin, nor-

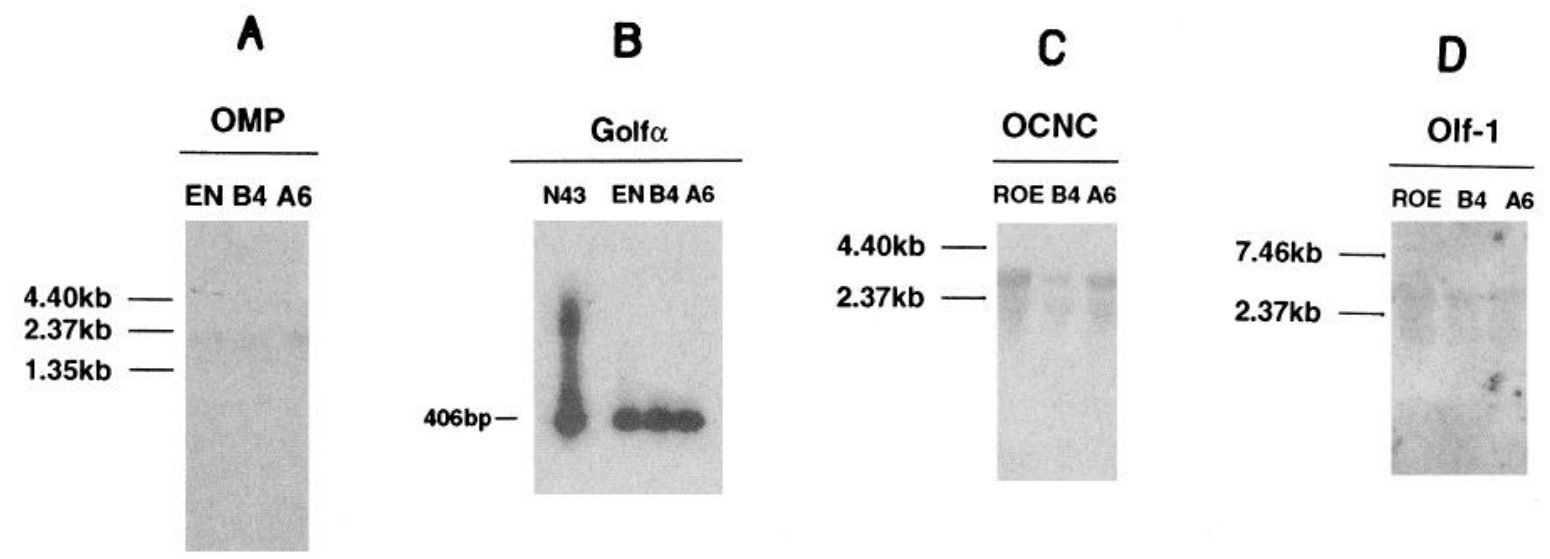

Figure 4. Expression of olfactory-associated genes in FNC-A6 and FNC-B4 long-term cell cultures. A, Northern hybridization of human OMP with FNC-A6 and FNC-B4 cells. Total RNA $(10 \mu \mathrm{g}$ per lane) was prepared as described in Materials and Methods from FNC-A6 ( $A 6)$, FNC-B4 $(B 4)$, and an esthesioneuroblastoma ( $E N)$ cell line (positive control). RNA samples were electrophoresed in $1.2 \%$ agarose/formaldehyde gel and hybridized with ${ }^{32}$ P-labeled human OMP ORF (Bulakova et al., 1994). An RNA ladder (GIBCO-Bethesda Research Labs) was used as size marker. $B$, RT-PCR analysis of human $\mathrm{G}_{\mathrm{olr}} \alpha$. Randomly primed cDNA from DNase I-digested mRNA (EN, B4, and $\left.A 6\right)$ and control $\mathrm{G}_{\text {or }} \alpha \mathrm{cDNA}(N 43)$ (Zigman et al., 1993) were amplified by PCR using G60/G61 primer pair specific for human $\mathrm{G}_{\text {olr }} \alpha$ as described in Materials and Methods. A fragment of the expected size (406 bp) was identified by Southern blotting with a human $\mathrm{G}_{\text {oir }} \alpha$ specific oligonucleotide as described in Materials and Methods. $C$ and $D$, Northern blot analysis of OCNC1 $(C)$ or olf- $1(D)$ expression; $2.5 \mu \mathrm{g}$ of polyA ${ }^{+}$RNA obtained from rat (Fischer 344 ) olfactory epithelium $(R O E)$, FNC-B4 (B4), or FNC-A6 $(A 6)$ were size fractionated and hybridized as described in Materials and Methods. An RNA ladder (GIBCO-Bethesda Research Labs) was used as size marker. 
A

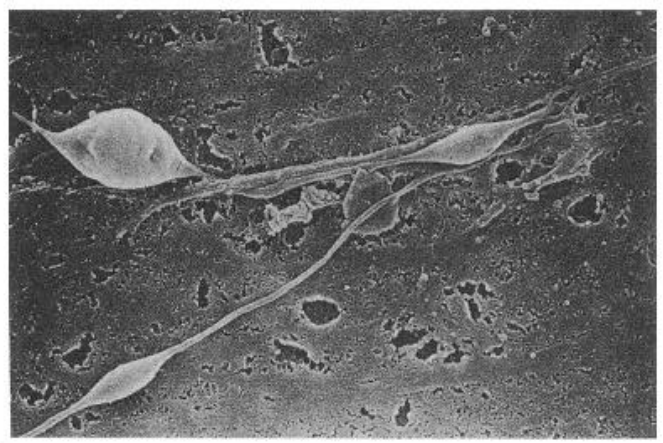

B

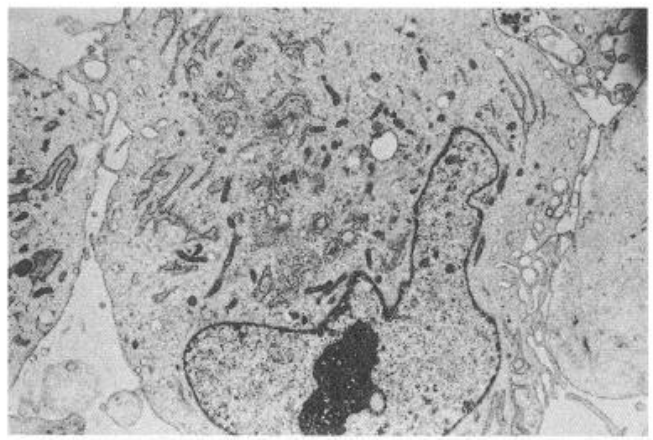

C

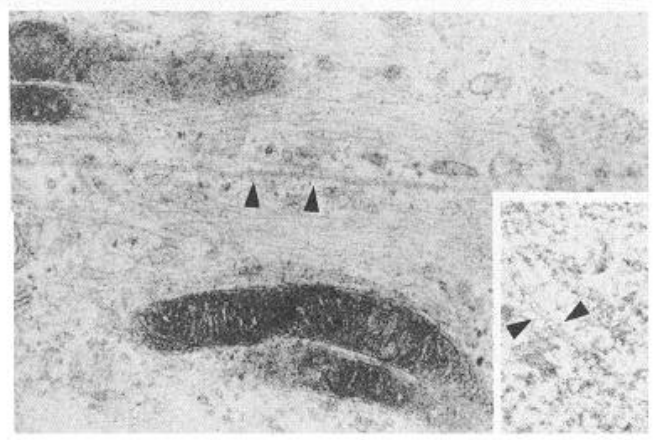

Figure 5. Ultrastructural analysis of long-term cell cultures from human olfactory neuroepithelium. Electron microscopic analysis of FNCA6 and FNC-B4 cells was performed as described in Materials and Methods. A, Scanning electron micrograph of FNC-A6 cells $(7500 \times)$ reveals processes of different length often presenting localized swellings. $B$, Transmission electron microscopy $(8800 \times)$ shows free and grouped ribosomes, Golgi apparatus, mitochondria and various inclusions of pigments and lipids. $C$, Higher magnification $(67,000 \times)$ reveals fibrillar and tubular cytoskeletal structures whose dimensions correspond to $10 \mathrm{~nm}$ and $20-30 \mathrm{~nm}$, respectively (arrows). The inset provide details of the tubular structures (arrows) at higher magnification $(85,000 \times)$.

adrenalin, isoproterenol, cholera toxin, and forskolin (Sigma, St. Louis, MO).

\section{Karyotype analysis}

Chromosome analysis was performed with both FNC-A6 and FNC-B4 by Moorhead procedure and banding analysis as previously described (Moorhead et al., 1960; Nowell et al., 1960) before and after cryogenic preservation, respectively, to evaluate the stability of these cells and their ability to withstand cryogenic freeze.

\section{Results}

\section{Cell cultures from human fetal olfactory neuroepithelium}

Clones were obtained from primary cultures of human fetal olfactory mucosa explants (Fig. $1 A, B$ ), by plating the cells at limiting dilution as described in Materials and Methods. A total of 54 colonies, composed of cells with different dimensions and morphologies were grown successfully. Most of them, however, were represented by cells expressing thin cytoplasmic processes and often bipolar shape (Fig. 1B). To verify whether these cultures contained olfactory precursors or members of the series of maturing olfactory receptor neurons, 10 clones were first selected by immunocytochemistry using antibodies directed against neuronal or olfactory markers. Next, we evaluated the expression of olfactory-associated genes followed by the ultrastructural, biochemical and functional analysis of the selected clones.

\section{Morphological, biochemical, and functional characterization}

Immunophenotyping and olfactory-associated gene expression. The olfactory receptor neuron is the only type of neuron in the olfactory epithelium (OE). To identify neuronal cells, among accessory non-neuronal cells, ten out of the 54 clones obtained were tested by immunocytochemistry using antibodies directed toward neuronal components (Fig. $2 A-C$, Table 1). Neuron specific enolase (NSE), a marker of neurons and neuroendocrine cells (Schmechel et al., 1978; Marangos et al., 1980), has been also described in human fetal olfactory neuroepithelium (Takahashi et al., 1984), and its expression is retained by olfactory neuroblast in vitro (Coon et al., 1989). Among the clones tested, intensive, diffuse staining by antibodies specific for NSE was detected with both the FNC-A6 and FNC-B4 cells (Fig. 2A, Table 1).

Intermediate filaments (IF) are cell and tissue specific components of the cytoskeleton (Liem et al., 1978; Lazarides, 1982; Osborn and Weber, 1982). As their constitutive units have a characteristic expression during cellular differentiation (Lazarides, 1982; Holtzer et al., 1982; Osborn and Weber, 1982; Shaw and Weber, 1982; Cochard et al., 1984; Stagaard et al., 1989), they may be used to identify both the cell type and the degree of maturation. Among IF, Vimentin (Vm) has a widespread distribution, being expressed by neuroepithelial cells in the neural tube and neural crest as well as by glial cells and mesenchymal derivatives (Bignami et al., 1982; Holtzer et al., 1982; Lazarides, 1982). In contrast, neurofilament proteins are specific to neuroblasts and neurons (Liem et al., 1978; Shaw and Weber, 1982; Scott et al., 1985). Vm-specific antibodies gave a diffuse, mostly perinuclear staining in about $60-70 \%$ of the cells in both FNCA6 and FNC-B4 cells (Fig. 2B, Table 1). NF-specific antibodies finely stained the cytoplasm, progressively intensifying in the proximal region of emerging cellular processes in $40-50 \%$ of the FNC-A6 and $20-30 \%$ of FNC-B4 cells (Fig. 2A, Table 1). Cytokeratin $(\mathrm{CK})$ represents a class of IF proteins characteristic of epithelial cells (e.g., Moll et al., 1982). Although keratinpositive cells are abundant in the basal cell layer within the OE that also contains the self-renewing neuronal progenitors, evidence suggests that neuronal precursors are keratin-negative cells migrating from the keratin-positive epithelial sheet during olfactory neurogenesis (Calof et al., 1989). Cytokeratin-specific antibodies did not stain FNC-A6 and FNC-B4 cells (Fig. 2B, Table 1), indicating these cells do not express epithelial markers.

Neural cell adhesion molecule (N-CAM) is a polysialylated 


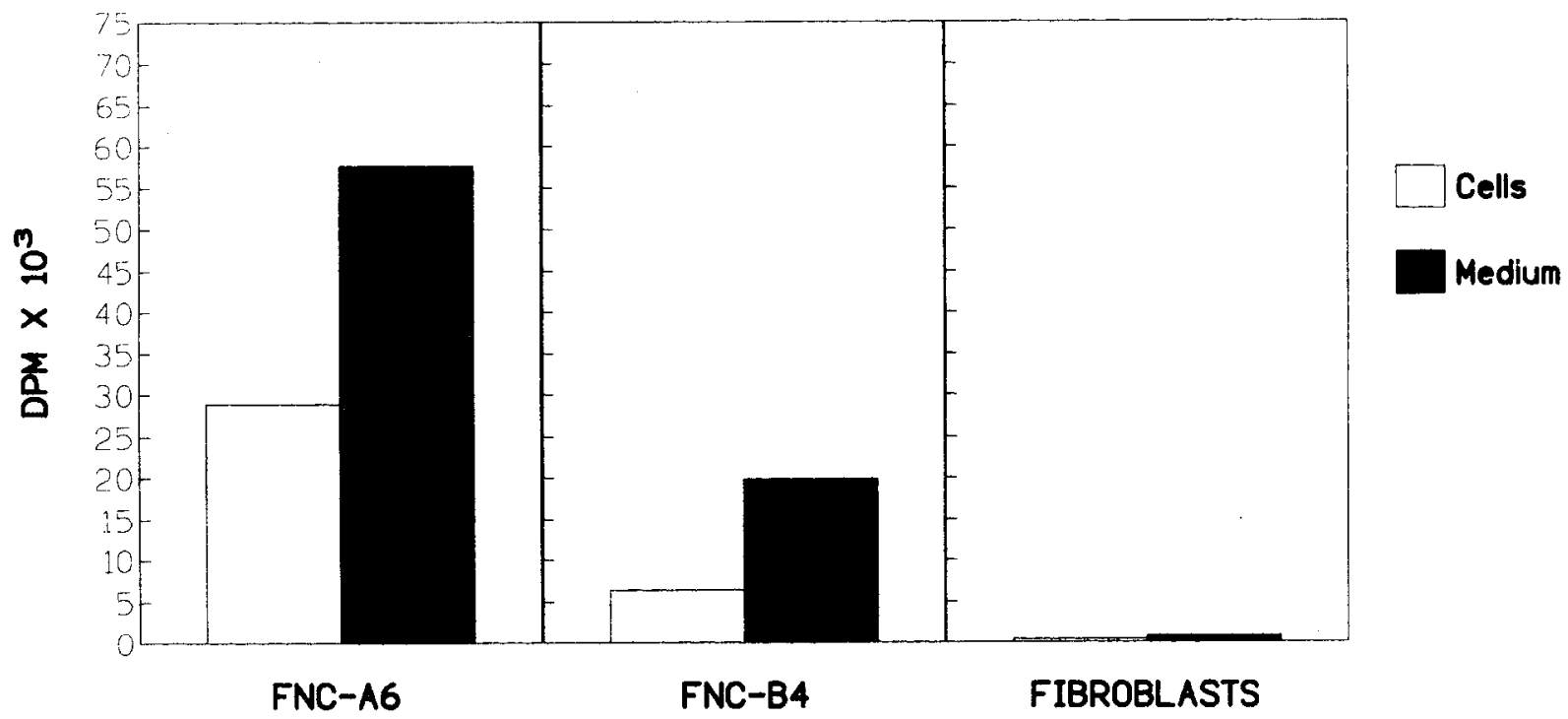

Figure 6. Long-term cell cuitures from the human fetal olfactory epithelium synthesize the dipeptide carnosine. Following $4 \mathrm{~d}$ incubation of the cells with ${ }^{3} \mathrm{H}-\beta$-alanine, media, and cell extracts were deproteinized and carnosine separated by high performance cation-exchange chromatography as described in Materials and Methods. Radioactivity was assessed by liquid scintillation counting. Human fibroblasts served as negative controls. Experiments, repeated twice, gave consistent results.

protein involved in cell-cell interaction (Schachner et al., 1990) that plays an important role during embryogenesis and development (Edelman, 1986; Sunshine et al., 1987). This adhesion molecule has been detected in both embryonic and adult brain (Aaron and Chesselet, 1989) as well as in mature olfactory neurons and their precursors (Mirayall et al., 1988, 1989; Calof et al., 1989). In the olfactory system N-CAM appears relatively late during differentiation as the most immature precursors lack its expression (Calof et al., 1989). Anti-N-CAM antibody diffusely stained both FNC-A6 and FNC-B4 cells (Fig. 2C). Consistent with the pattern of expression of this protein in developing ORN, both the embryonic and adult forms of N-CAM were identified in the FNC-A6 and FNC-B4 cells by Western analysis (Fig. 3).

Olfactory marker protein (OMP), is a $18.7 \mathrm{kDa}$ cytosolic protein of unknown function that has been specifically identified in cell bodies and neurites of olfactory sensory neurons (e.g., Margolis, 1972; Hartman et al., 1975; Keller et al., 1975). Anti-OMP sera gave a diffuse, mostly cytoplasmic staining with both FNCA6 and FNC-B4 cells (Fig. 2C). However, as the possibility of nonspecific staining has been previously reported by immunofluorescence technique (Coon et al., 1989), immunoblot analysis was performed (Fig. 3). The results confirmed OMP expression with both FNC.A6 and FNC.-B4 cells (Fig. 3). In addition, Northern blot analysis indicated that both FNC-A6 and FNC-B4 cells express the human OMP gene ORF (Fig. 4A). To further characterize the functional maturity of these cells we next examined the expression of specialized proteins involved in the olfactory signal transduction. Olfactory signal transduction is mediated by a process involving a $G$ protein-coupled cascade using CAMP as an intracellular second messenger (Pace et al., 1985; Buck and Axel, 1991) that in turn activate an olfactory cyclic nucleotide-gated channel (Nakamura and Gold, 1987; Dhallan et al., 1990).$G_{\text {olf }} \alpha$ is a stimulatory G-protein that participate in signal transduction in the olfactory neuroepithelium (Jones and Reed, 1989). In rats, this protein is expressed on prenatal day 17 , when selective response to odorants begins to be observed (Dau et al., 1991). Expression of a human isoform of $\mathrm{G}_{\text {oli }} \alpha$ has been confirmed in human olfactory neuroepithelium and, to a lesser extent, in the basal ganglia and neuroendocrine tissues (Zigman et al., 1993). Both FNC-A6 and FNC-B4 cells express $\mathrm{G}_{\mathrm{off}} \alpha$ mRNA, as indicated by RT-PCR analysis (Fig. $4 B$ ). The olfactory cyclic nucleotide-gated channels (OCNC) are directly activated by both cAMP and cGMP (Nakamura and Gold, 1987; Kurahashi and Kaneko, 1989; Kurahashi, 1990; Firestein et al., 1991). OCNC-encoding cDNA has been recently cloned from rat (Dhallan et al., 1990), cow (Ludwig et al., 1990), and catfish (Goulding et al., 1992). Northern blot analysis for rOCNCl (Dhallan et al., 1990) showed a major hybridizing species of about $3.3 \mathrm{~kb}$, almost as similar size as in rat, with both FNC-A6 and FNC-B4 cells (Fig. 4C). In addition, Northern blot analysis indicated that both $\mathrm{FNC}^{-\mathrm{A} 6}$ and $\mathrm{FNC}-\mathrm{B} 4$ express $\mathrm{Olf}-1$ (Fig. 4D), an early B cell factor (EBF)-related transcriptional factor which appear to be exclusively expressed in the olfactory receptor neurons and their precursors (Wang and Reed, 1993). Olf- 1 contains helix-loop-helix motif and is thought to bind the regulatory sequences of several olfactory-specific genes including OMP, OCNC1, type III adenylyl cyclase, and $\mathrm{G}_{\text {olf }}$ (Ibid.). These results strongly support the identification of these cells and suggest that some degree of maturity is expressed in vitro.

Ultrastructural studies. Scanning electron micrograph (Fig. $5 A$ and data not shown) of bipolar shaped cells shows processes of different length. Shorter processes often present localized swellings suggesting the knob-like structures previously described in histological sections of olfactory mucosa from human fetuses (Pyatkina, 1982). Transmission electron microscopy (Fig. $5 B$ and data not shown) reveals a cytoplasm rich in ribosomes as well as polyribosomes, Golgi apparatus, mitochondria, a pronounced rough endoplasmic reticulum and various inclusions of pigments and lipids. Nuclei are irregularly shaped, generally containing a single nucleolus. Higher magnification reveals cytoskeletal constituents as fibrillar and tubular structures with smooth contour and variable length whose dimensions, corre- 


\section{A}

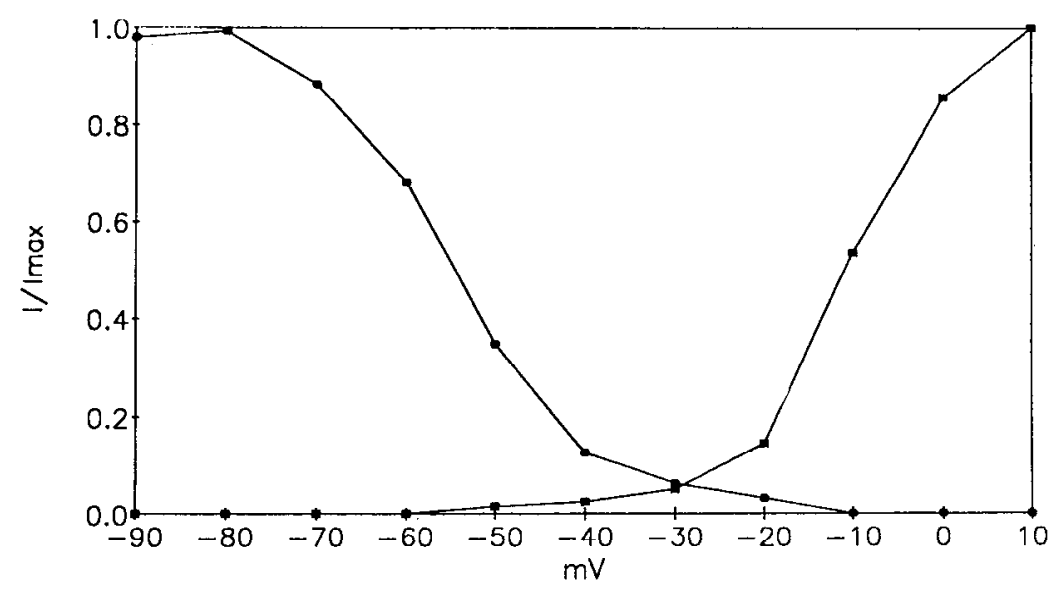

B

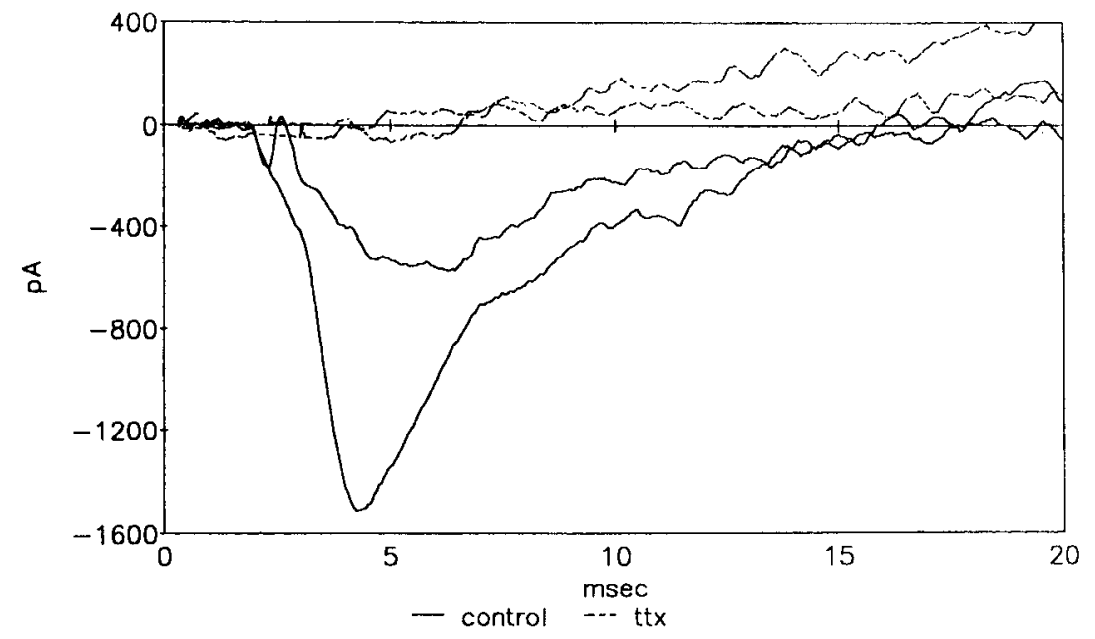

Figure 7. Cell cultures from the human fetal olfactory epithelium are electrically excitable. Sodium currents were recorded under the voltage-clamp configuration of the whole-cell patchclamp technique in both FNC-A6 and FNC-B4 cells as described in Materials and Methods. The sodium currents shows activation-inactivation characteristics $(A)$ and tetrodotoxin-sensitiveness $(B)$ with the typical pattern described for neuronal sodium channels (Armstrong et al., 1974; Hille, 1992). sponding to $10 \mathrm{~nm}$ and $20-30 \mathrm{~nm}$, respectively, are consistent with neurofilaments and neurotubules (Fig. $5 \mathrm{C}$ ).

Biochemical studies. The dipeptide carnosine has been identified in ORN and has been implicated as a possible neurotransmitter in the vertebrate olfactory system (e.g., Margolis, 1974; Burd et al., 1982). After incubating the cells with ${ }^{3} \mathrm{H}-\beta$-alanine, chromatographically purified, radioactive carnosine was isolated from cellular extracts of FNC-A6 and FNC-B4 cells yet not from normal human fibroblasts (Fig. 6). In addition, radiolabeled carnosine was detected in conditioned media collected from the FNC-A6 and FNC-B4 cell cultures at the same time point at which the cells were harvested and cellular extracts prepared (Fig. 6). The amount of labelled carnosine detected in the conditioned media parallels the different intracellular levels detected in the two cell cultures (Fig. 6) and did not appear to be a consequence of increased cell death. In fact, cellular viability, as measured by trypan blue exclusion test, was always less than $5 \%$.

Electrophysiological recordings. To evaluate whether the FNC-A6 and FNC-B4 cells were endowed with ionic channels characteristic of excitable cells (Hille, 1992), electrophysiological studies were performed by the whole-cell patch-clamp tech- nique as described in Materials and Methods. Voltage-gated sodium currents were recorded under the voltage clamp configuration, in both FNC-A6 and FNC-B4 cells. These currents showed TTX sensitiveness as well as activation-inactivation characteristics (Fig. 7A,B). This pattern is typical of the sodium channels that elicit action potentials in neuronal cells (Armstrong et al., 1974; Hille, 1992).

Functional analysis. The unique functional characteristic of ORN is their ability to respond to odors. Adenylyl cyclase has been shown to be a key enzyme in transmembrane signaling in olfactory sensory neurons and a cAMP-mediated pathway of olfactory signal transduction has been well described (e.g., Pace et al., 1985; Lowe et al., 1989; Bakalyar et al., 1990; Breer et al., 1990). Functional responses (cAMP accumulation) were reproducibly obtained in FNC-A6 (Fig. 8) after the exposure to micromolar concentrations of simple aromatic chemicals (e.g., Sklar et al., 1986). A time course analysis of odorant responses indicated that the levels of adenylate cyclase activity augmented 5 min after exposure to odorants (Fig. 9) and increased linearly with time reaching a peak $30 \mathrm{~min}$ after stimulation (Fig. 9). Titration experiments (Fig. 10) indicated that the levels of adenylate cyclase activity were significantly augmented $(p<$ 
FNC-A6

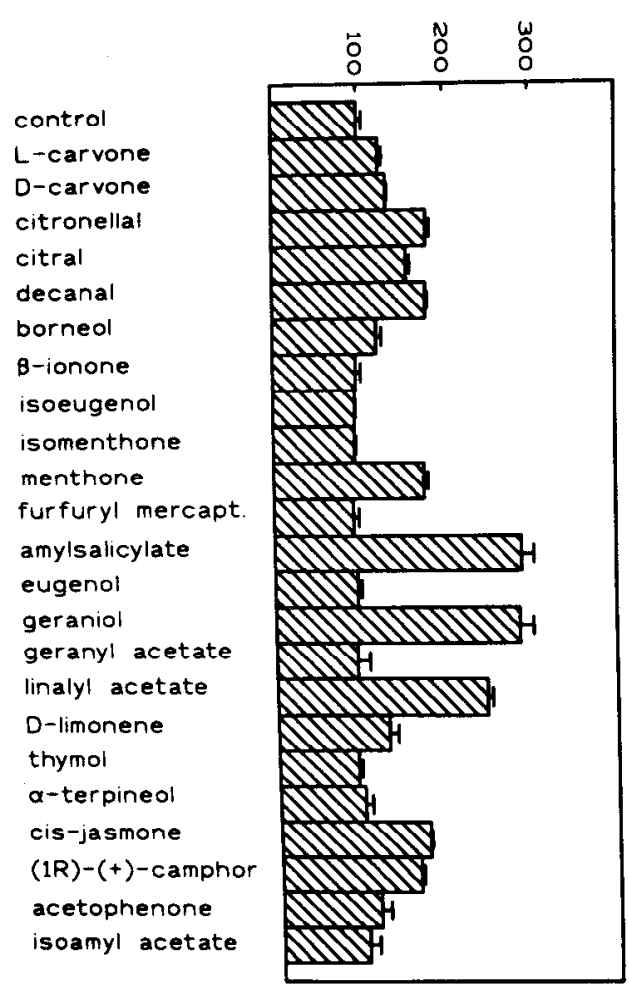

FNC-B4

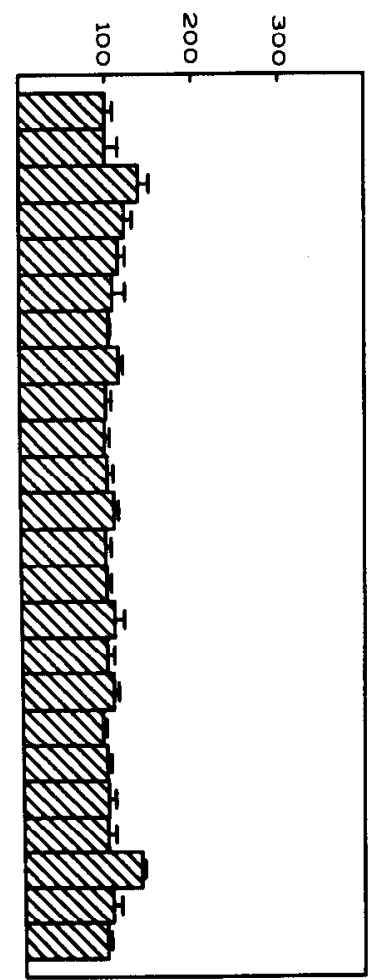

WRT

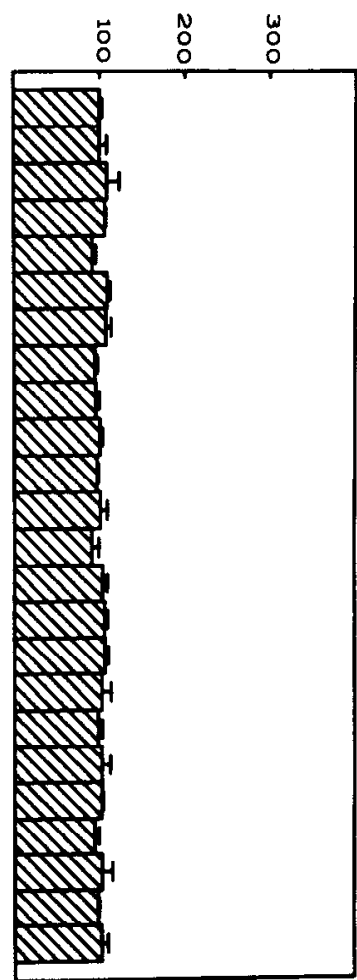

Figure 8. Intracellular cAMP accumulation responses of FNC-A6 and FNC-B4 Cells to odorant stimuli. Intracellular cAMP accumulation was determined in FNC-A6, FNC-B4 and WRT cell line as described in Materials and Methods. Concentrations of aromatic chemicals were all 100 $\mu \mathrm{M}$. Results are expressed as the percentage stimulation over the basal level (basal levels were $0.48,0.23$, and $0.57 \mathrm{cAMP} \mathrm{pmol} / \mu \mathrm{g}$ DNA in FNCA6, FNC-B4, and WRT cells, respectively). Values are the mean \pm SEM of three or more experiments.
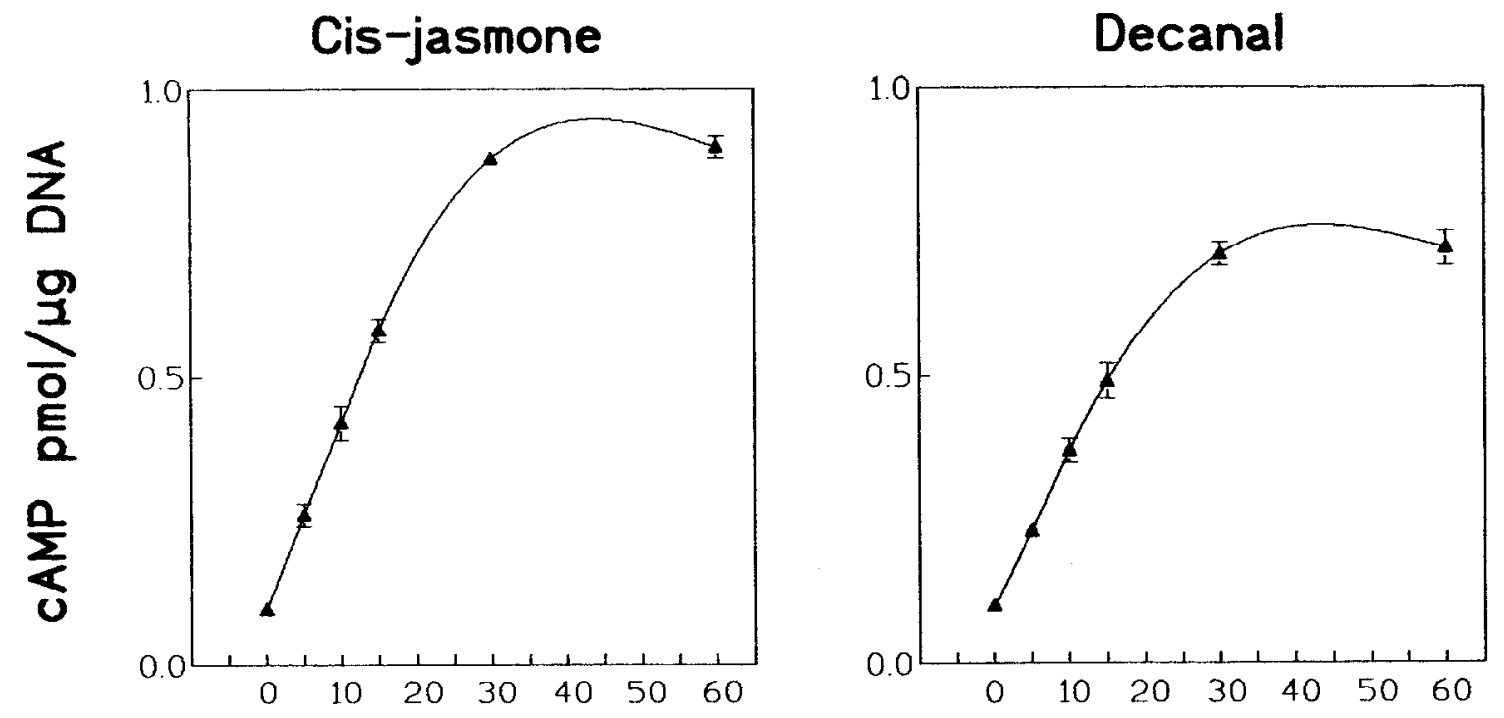

\section{Time $(\min )$}

Figure 9. Time-course analysis of odorant responses in FNC-A6 cells. Intracellular cAMP accumulation was determined in FNC-A6 cells in the presence of $100 \mu \mathrm{M}$ concentrations of two different odorants (Cis-jasmone and Decanal) at different time points (5 min to $60 \mathrm{~min}$ ). Odorant responses are evident $5 \mathrm{~min}$ after stimulation and increase linearly with time reaching a peak at $30 \mathrm{~min}$. The results represent a mean (three or more independent experiments) \pm SEM of $\mathrm{cAMP}$ pmol/ $\mu \mathrm{g}$ DNA. 


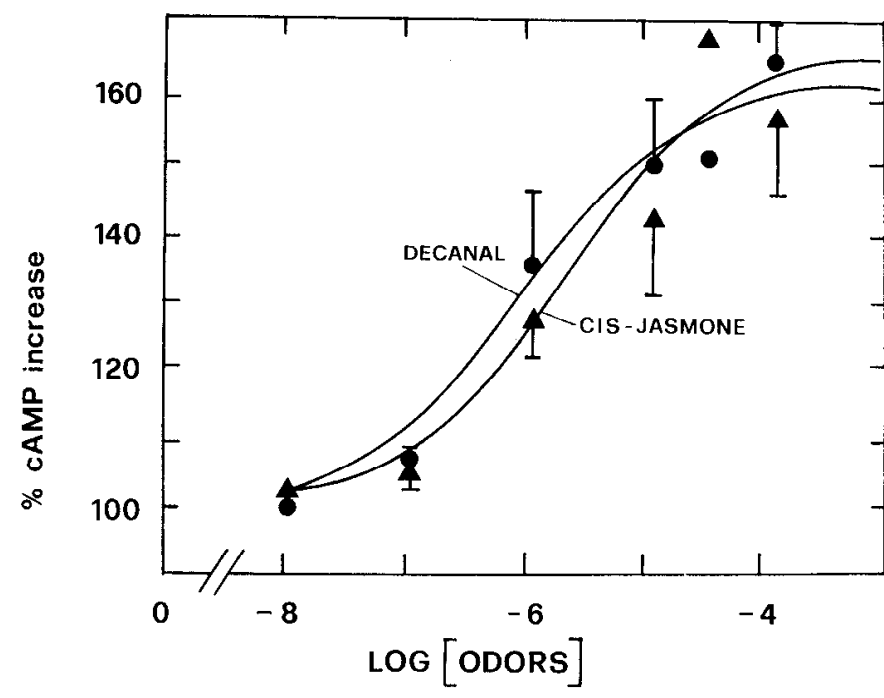

Figure 10. Effects of odorant concentration on adenylate cyclase activity in FNC-A6 cells. Serial concentrations of odorants (Decanal and Cis-jasmone) stimulate a dose-dependent intracellular cAMP accumulation in FNC-A6 cells. The results represent the mean (three or more independent experiments) \pm SEM of cAMP pmol/ $\mu \mathrm{g}$ DNA. Mathematical analysis (De Lean et al., 1978) was performed by the ALLFIT software.

$0.004)$ with concentrations of aromatic chemicals comprised between $10^{-7} \mathrm{M}$ and $10^{-6} \mathrm{M}$ and increased with increasing odorant concentrations $(p<0.0001)$ (Fig. 10). Mathematical analysis (De Lean et al., 1978) of three different curves for each stimulant indicates that the different curves share similar $\mathrm{EC}_{50}$ (Cisjasmone $\mathrm{EC}_{50}=1.7 \pm 0.7 \mu \mathrm{M}$; Decanal $\mathrm{EC}_{50}=0.99 \pm 0.8$ $\mu \mathrm{M})$. Maximal stimulation over the basal value were $58.6 \pm$ $12 \%$ and $59 \pm 10.2 \%$ with Cis-jasmone and Decanal, respectively. The FNC-B4 cells, the rat thyroid cell line WRT (Brandi et al., 1987) as well as the human neuroblastoma cell line SHSY5Y (Ciccarone et al., 1989) used as negative controls were not responsive to any of the tested odorants (Fig. 8 and data not shown), under the experimental conditions examined. The inability of FNC-B4 to respond to chemical odorants was not duc to a functional defect in their cAMP signaling pathway as both FNC-A6 and FNC-B4 exhibited increases in intracellular cAMP in the presence of nonodorant standard stimulants such as adrenalin, noradrenalin, isoproterenol, cholera toxin, and forskolin (Fig. 11).

Karyotype analysis. Chromosome analysis, performed at early times of characterization (Fig. 12, upper panels) and after cryogenic preservation (Fig. 12, lower panels), respectively, indicated that both FNC-A6 and FNC-B4 cells have a normal human diploid chromosome pattern and are able to withstand cryogenic freeze.

\section{Discussion}

We established two clonal long-term cultures of neuronal origin from dissociated primary cultures of human developing olfactory ncurocpithelium. The morphological, immunocytochemical, biochemical, and functional properties of these cells support their identification as maturing olfactory receptor neurons. Morphologically, the cultured cells show cytoplasmic processes and often a bipolar shape as previously described in primary cultures of olfactory neurons (Coon et al., 1989; Pixley et al., 1990; Ronnett et al., 1991; Wolozin et al., 1992). Electron microscopy

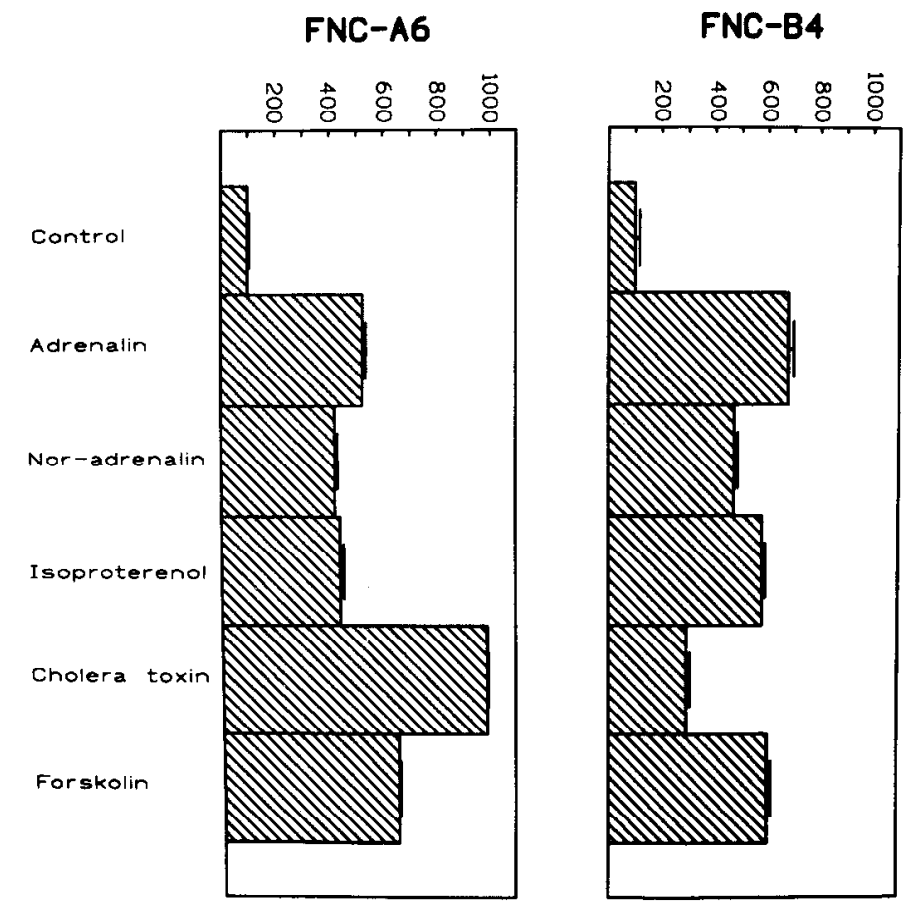

Figure 11. Intracellular cAMP accumulation response of FNC-A6 and FNC-B4 cells to standard nonodorant cAMP stimulants. Both FNC-A6 and FNC-B4 cells respond to standard nonodorant cAMP stimulants. All the stimulants were used at $10^{-4} \mathrm{M}$ concentrations, except cholera toxin $\left(10^{-6} \mathrm{M}\right)$ and forskolin $\left(10^{-5} \mathrm{M}\right)$. Results are expressed as the percentage stimulation over the basal level. Values are the mean \pm SEM of three or more independent experiments.

reveals cells with thin cytoplasmic processes and localized swellings, while the cytoplasmic ultrastructure shows the presence of cytoskeleton tubular and fibrillar components. These results are consistent with previous observations in histological sections of human fetal olfactory neuroepithelium (Pyatkina, 1982) and suggest that some degree of maturation could be expressed by embryonal olfactory neuroblasts in vitro.

Immunocytochemical analysis is consistent with previously published studies of olfactory neurons. The absence of cytokeratin and the expression of neuron-specific enolase and vimentin correspond to well known characteristics of differentiating ORN (e.g., Takahashi et al., 1984; Schwob et al., 1986; Calof et al., 1989; Coon et al., 1989). Both vimentin and neurofilaments have been detected in developing neuroepithelia as well as in olfactory neurons (e.g., Cochard et al., 1984; Takahashi et al., 1984; Schwob et al., 1986; Stagaard et al., 1989; Gorham et al., 1991). The reciprocal relationship between vimentin and neurofilaments during the development of the central and peripheral nervous system, indicate that neurofilament expression is preceded by that of vimentin and both types of intermediate filaments seem to coexist in the same cell for a short period of time (Bignami et al., 1982; Holtzer et al., 1982; Jacobs et al., 1982; Drager, 1983; Cochard et al., 1984; Stagaard et al., 1989; Gorham et al., 1991). Thus, coexpression of vimentin and neurofilaments, as detected in a fraction of the cells in our cultures, suggests an "intermediate" degree of maturity. On the other hand, the detection of N-CAM and the expression of human OMP in both FNC-A6 and FNC-B4 cells is consistent with the pattern described in more mature olfactory neurons (Monti-Graziadei et al., 1980; Miragall et al., 1982, 1988, 1989; Pace et al., 1986; 


\section{FNC-A6}
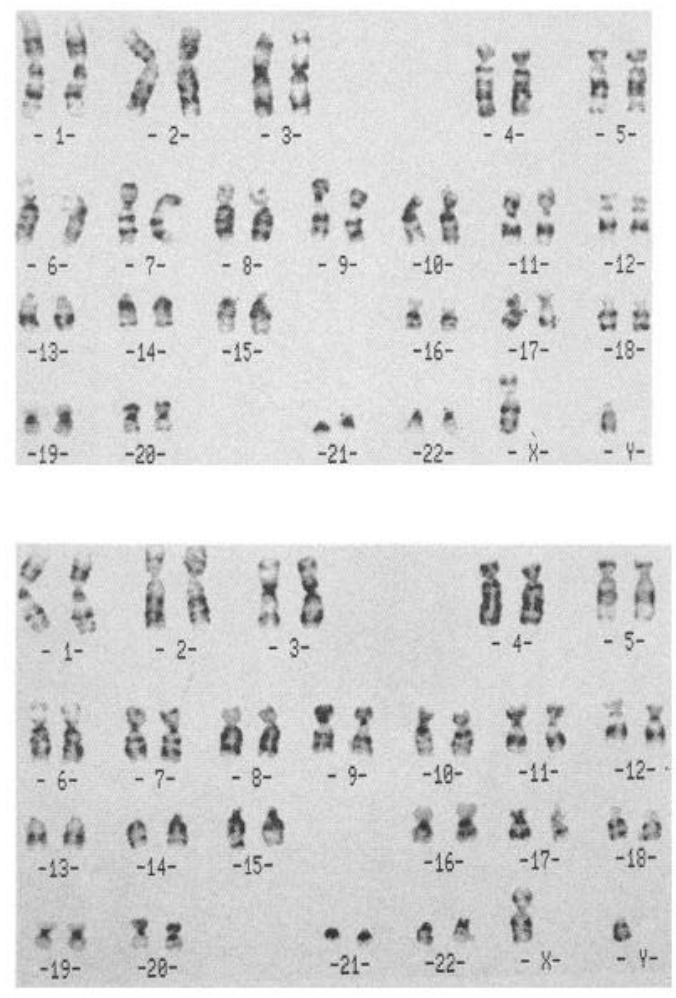

\section{FNC-B4}
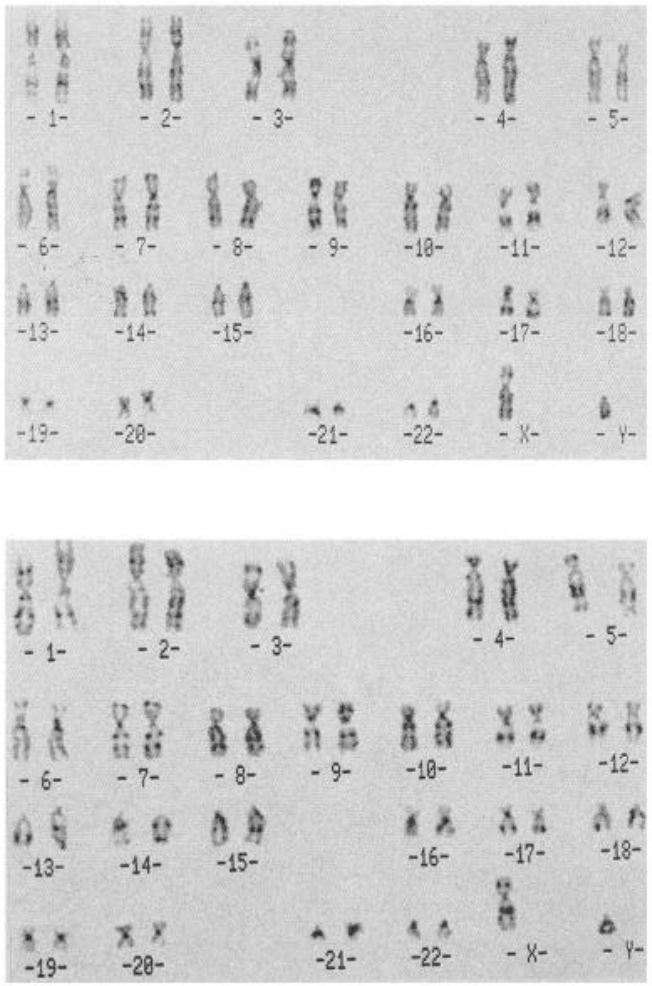

Figure 12. Karyotype analysis of FNC-A6 and FNC-B4 before and after cryogenic preservation. Chromosome analysis was performed with both FNC-A6 and FNC-B4 before (upper panels) and after cryogenic preservation (lower panels). Both cell cultures show a normal diploid chromosome pattern that is consistently maintained after cryogenic preservation (lower panels).

Calof et al., 1989). The expression of genes involved in the olfactory signal transduction such as $\mathrm{G}_{\text {orr }} \alpha$ and OCNCl as well as the detection of olf- 1 provide further evidence of functional maturity (Breer et al., 1990; Dhallan et al., 1990; Wang and Reed, 1993). These results not only support the olfactory identification of FNC-A6 and FNC-B4 cells but also suggest that these cultures may derive from immature precursors (stem cells) and are composed, at all times, by cells at different stages of maturation. This may also explain the coexistence of different morphologies with both FNC-A6 and FNC-B4 clones in vitro.

Results of biochemical and functional studies are consistent with the identification of these cells and provide further evidence of their functional maturity. Carnosine synthetase activity was detected in both cell cultures, as indicated by the incorporation of labeled precursors into chromatographically purified carnosine. In addition, the detection of extracellular carnosine in the absence of detectable cell death indicates that the dipeptide is released by the cells in vitro. Carnosine has been suggested as potential olfactory neurotransmitter (e.g., Margolis, 1974; Rochel et al., 1982). It is present in olfactory tissues and muscles of many vertebrates and is synthesized enzymatically from its component amino acids by the carnosine synthetase (e.g., Horinishi et al., 1978; Margolis et al., 1985). In olfactory tissues, carnosine synthesis appears early during ontogenesis and is localized exclusively to the chemoreceptor neurons (Margolis et al., 1985).

Voltage-gated sodium currents have been detected in both FNC-A6 and FNC-B4 cells. Sodium channels are characteristically present in neurons (cell bodies and axons), in vertebral skeletal and cardiac muscles and different endocrine glands (e.g., Hille, 1992). In neurons $\mathrm{Na}^{+}$channels have the primary function to generate the rapid regenerative upstroke of an action potential (Hille, 1992). The demonstration of voltage-gated sodium channels in our cells, the TTX sensitivity and the activation-inactivation curve of the $\mathrm{Na}^{+}$currents indicate that these cells are electrically excitable and that action potentials can be elicited (Schubert et al., 1985).

Finally, the ability to recognize and sensitively discriminate aromatic molecules through specific receptors is the unique characteristic of olfactory receptor neurons. cAMP plays a crucial role in the molecular mechanisms of olfaction, acting as a second messenger in the olfactory transduction process (Pace et al., 1985; Lowe et al., 1989; Bakalyar et al., 1990; Breer et al., 1990). Therefore, intracellular cAMP accumulation in response to aromatic chemicals represents a specific and sensitive test to functionally identify mature olfactory receptor neurons (Pace et al., 1985; Lowe et al., 1989). Selective, odorant-dependent cAMP responses have occurred in one of the cell cultures (FNCA6) with physiologically relevant concentrations of simple odorant compounds (Shirley et al., 1986). Specific cAMP accumulation has been observed to be slower and last longer than previously reported in nonhuman models (Coon et al., 1989; Lowe et al., 1989; Pixley et al., 1990; Ronnett et al., 1993), suggesting that the olfactory response may follow different kinetics in different biological systems. Since these cells derive from early fetal explants, our results may also suggest that a specialized function such as the odorant response appears relatively early during olfactory development in humans. On the other hand, as 
suggested by the immunocytochemical data, these cultures may originate from stem cell populations consisting at all times of a mixture of cells at various stages of differentiation. The variable number of cells spontaneously differentiating in vitro may account for the detection of specialized functions. The lack of intracellular cAMP accumulation in FNC-B4 cells in the presence of the relatively small number of odorants tested is not unexpected. In fact, different populations of olfactory receptor neurons are thought to respond to a restricted pattern of odorant stimuli (Sklar et al., 1986; Coon et al., 1989; Pixley et al., 1990; Buck and Axel, 1991). Therefore, the absence of odorant response in FNC-B4 may simply reflect a distinct odor specificity of this clone. Alternatively, as the FNC-B4 cells were established from earlier fetal explants ( 8 weeks of gestation), they may be represented by immature precursors lacking the ability to generate functionally differentiated cells in vitro, in the absence of crucial environmental stimuli.

The cell cultures we have reported have both neuronal and olfactory properties, consistent with their identification as olfactory neuroblasts. The availability of human olfactory neuronal precursors should greatly assist in elucidating mechanisms of olfactory neurogenesis, differentiation, and function. In addition, human neuronal long-term cell cultures may provide in vitro models to study mechanisms of pathological processes leading to neurological disease.

\section{References}

Aaron LI, Chesselet MF (1989) Heterogeneous distribution of polysialylated N-CAM during postnatal development and in the adult. An immunohistochemical study in the rat brain. Neuroscience 28:701710.

Armstrong CM, Bezanilla F (1974) Charge movement associated with the opening and closing of the activation gates of the Na channels. J Gen Physiol 63:533-552.

Bakalyar HA, Reed RR (1990) Identification of a specialized adenylyl cyclase that may mediate odorant detection. Science 250:1403-1406.

Bignami A, Raju T, Dahl D (1982) Localization of vimentin, the nonspecific intermediate filament protein, in embryonal glia and in early differentiative neurons. Dev Riol 91:286-295

Brandi ML, Rotella CM, Mavilla C, Franceschelli F, Tanini A, Toccafondi R (1987) Insulin stimulates cell growth of a new strain of differentiated rat thyroid cells. Mol Cell Endocrinol 54:91-103.

Breer H, Boekhoff I, Tareilus E (1990) Rapid kinetics of second messenger formation in olfactory transduction. Nature 345:65-68.

Buck L, Axel R (1991) A novel multigene family may encode odorant receptors: a molecular basis for odorant recognition. Cell 65:175187.

Bulakova OI, Rama Krishna NS, Getchell TV, Margolis FL (1994) Human and rodent OMP genes: conservation of structural and regulatory motif and cellular localization. Genomics 20:452-462.

Burd GD, Davis BJ, Macrides F, Grillo M, Margolis FL (1982) Carnosine in primary afferents of the olfactory system: an autoradiographic and biochemical study. I Neurosci 2:244-255

Cain WS, Gent JF (1986) Use of odor identification in clinical testing of olfaction. In: Clinical measurement of taste and smell (Meiselman HL, Rivlin RS, eds), pp 170 186. New York: Macmillan.

Calof AL, Chikaraishi DM (1989) Analysis of neurogenesis in a mammalian neuroepithelium: proliferation and differentiation of an olfactory neuron precursur in vitro. Neuron 3:115-127.

Chuah MI, David S, Blaschuk O (1991) Differentiation and survival of rat olfactory epithelial neurons in dissociated cell culture. Dev Brain Res 60:123-132.

Ciccarone V, Spengler BA, Meyers MB, Biedler JL, Ross RA (1989) Phenotypic diversification in human neuroblastoma cells: expression of distinct neural crest lineages. Cancer Res 49:219-225.

Cochard P, Paulin D (1984) Initial expression of neurofilaments and vimentin in the central and peripheral nervous system of the mouse embryo in vivo. J Neurosci 4:2080-2094

Coon HG, Curcio F, Sakaguchi K, Brandi ML, Swerdlow RD (1989)
Cell cultures of neuroblasts from rat olfactory epithelium that show odorant responses. Proc Natl Acad Sci USA 86:1703-1707.

Dau B, Menco BPM, Bruch RC, Danho W, Farbman A (1991) Appcarance of the transduction proteins $G_{s} \alpha$ and adenylate cyclase in the olfactory epithelium of rats occurs on different prenatal days. Chem Senses 16:511-512.

De Lean A, Munson PJ, Rodbard D (1978) Simultaneous analysis of families of sigmoidal curves: application to bioassay, radioligand assay, and physiological dose-response curves. Am J Physiol 235:97102.

Dhallan RS, Yau K, Schrader K, Reed R (1990) Primary structure and functional expression of a cyclic nucleotide-activated channel from olfactory neurons. Nature 347:184-187.

Drager UC (1983) Coexistence of neurofilaments and vimentin in a neurone of adult mouse retina. Nature 303:169-172.

Edelman GM (1986) Cell adhesion molecules in the regulation of animal form and tissue pattern. Annu Rev Cell Biol 2:81-116.

Firestein S, Darruw B, Shepherd GM (1991) Activation of the sensory current in salamander olfactory receptor neurons depends on a $G$ protein mediated cAMP second messenger system. Neuron 6:825835.

Gorham JD, Ziff EB, Baker H (1991) Differential spatial and temporal expression of two type III intermediate filament proteins in olfactory receptor neurons. Neuron 7:485-497.

Goulding EH, Ngai J, Kramer R, Colicos S, Axel R, Siegelbaum SA Chess A (1992) Molecular cloning and single-channel properties of the cyclic nucleotide-gated channel from catfish olfactory neurons. Neuron 8:45-58.

Graziadei PPC (1973) Cell dynamics in the olfactory mucosa. Tissue Cell 5:113-131.

Graziadei PPC, Monti-Graziadei GA (1978) Continuous nerve cell renewal in the olfactory system. In: Development of sensory systems (Jacobsen M, ed), pp 55-83. Berlin: Springer.

Graziadei PPC, Monti-Graziadei GA (1979) Neurogenesis and neuron regeneration in the olfactory system of mammals. I. Morphological aspects of differentiation and structural organization of the olfactory neurons. J Neurocytol $8: 1-18$.

Hamill OP, Marty A, Neher E, Sakmann B, Sigworth FJ (1981) Improved patch-clamp techniques for high resolution current recording from cells and cell-free membrane patches. Pfluegers Arch Eur J Physiol 391:85-100.

Hartman BK, Margolis FL (1975) Immunofluorescence localization of the olfactory marker protein. Brain Res 96:176-180.

Hille B (1992) Ionic channels of excitable membranes, $2 d$ ed. Sunderland, MA: Sinauer.

Holtzer H, Bennet GS, Tapscott SJ, Croop JM, Toyama Y (1982) Intermediate-size filaments: changes in synthesis and distribution in cells of the myogenic and neurogenic lineages. Cold Spring Harbor Symp Quant Biol 46:317-329.

Horinishi H, Grillo M, Margolis FL (1978) Purification and characterization of carnosine synthetase from mouse olfactory bulb. J Neurochem 31:909-919.

Jacobs M, Choo QL, Thomas C (1982) Vimentin and 70K neuro-filament protein co-exist in embryonic neurones from spinal ganglia. J Neurochem 38:969-977.

Jones DT, Reed RR (1987) Molecular cloning of five GTP-binding proteins cDNA species from rat olfactory neuroepithelium. J Biol Chem 262:14241-14249.

Jones DT, Reed RR (1989) $\mathrm{G}_{\text {es: }}$ : an olfactory neuron specific G-protein involved in odorant signal transduction. Science 244:790-795.

Keller A, Margolis FL (1975) Immunological studies of the rat olfactory marker protein. J Neurochem 24:1101-1106.

Kurahashi T (1990) The response induced by intracellular cyclic AMP in isolated olfactory receptor cells of the newt. J Physiol (Lond) 419 : 177-192.

Kurahashi T, Kaneko A (1991) High density cAMP-gated channels at the ciliary membrane in the olfactory receptor cell. NeuroReport $2: 5-8$.

Labarca C, Paigen K (1980) A simple, rapid, and sensitive DNA assay procedure. Anal Biochem 102:344-352.

Lazarides E (1982) Intermediate filaments: a chemically heterogeneous developmentally regulated class of proteins. Annu Rev Biochem 51: 219-250.

Liem RKH, Yen SH, Salomon GD, Shelanski ML (1978) Intermediate filaments in nervous tissues. J Cell Biol 79:637-645. 
Lowe G, Nakamura T, Gold GH (1989) Adenylate cyclase mediates olfactory transduction in a wide variety of odorants. Proc Natl Acad Sci USA 86:5641-5645.

Ludwig J, Margalit T, Eisman E, Lancet D, Kaupp UB (1990) Primary structure of cAMP-gated channel from bovine olfactory epithelium. FEBS Lett 270:24-29.

Maillet M (1959) Modifications de la technique de Champy au tétraoxyde d'osmium-iodure de potassium. Résultats de sons, application à l'étude des fibres nerveuses. C R Soc Biol 6:939-940.

Marangos PJ, Schmechel DE, Parma AM, Goodwin FK (1980) Developmental profile of neuron-specific (NSE) and non-neuronal (NNE) enolase. Brain Res 190:185-193.

Margolis FL (1972) A brain protein unique to the olfactory bulb. Proc Natl Acad Sci USA 69:1221-1224.

Margolis FL (1974) Carnosine in the primary olfactory pathway. Science 184:909-911.

Margolis FL, Grillo M, Kawano T, Farbman AI (1985) Carnosine synthesis in olfactory tissue during ontogeny: effect of exogenous $\beta$-alanine. J Neurochem 44:1459-1464.

Miragall F, Monti Graziadei GA (1982) Experimental studies on the olfactory marker protein. II. Appearance of the olfactory marker protein during differentiation of the olfactory sensory neurons of mouse: an immunohistochemical and autoradiographic study. Brain Res 239: $245-250$.

Miragall F, Kadmon G, Husmann M, Schachner M (1988) Expression of cell adhesion molecules in the olfactory system of the adult mouse: presence of the embryonic form of N-CAM. Dev Biol 129:516-531.

Miragall F, Kadmon G, Schachner M (1989) Expression of L1 and $\mathrm{N}$-CAM cell adhesion molecules during development of the mouse olfactory system. Dev Biol 135:272-286.

Moll R, Franke WW, Schiller DL, Geiger B, Krepler R (1982) The catalog of human cytokeratins: patterns of expression in normal epithelia, tumors, and cultured cells. Cell 31:11-24.

Monti-Graziadei GA, Stanley RS, Graziadei PPC (1980) The olfactory marker protein in the olfactory system of the mouse during development. Neuroscience 51:1239-1252.

Moorhead PS, Nowell PC, Mellman WJ, Battips DM, Hungerford DA (1960) Chromosome preparations of leukocytes cultured from human peripheral blood. Exp Cell Res 20:613-616.

Nakamura T, Gold GH (1987) A cyclic nucleotide-galed conductance in olfactory receptor cilia. Nature 325:342-344.

Nowell PC, Hugerford DA (1960) A minute chromosome in human chronic granulocytic leukemia. Science 132:1497-1499.

Osborn M, Weber K (1982) Intermediate filaments: cell type specific markers in differentiation and pathology. Cell 31:303-306.

Pace U, Hanski E, Salomon Y, Lancet D (1985) Odorant-sensitive adenylate cyclase may mediate olfactory reception. Nature 316:255258.

Pixley SK, Pun YK (1990) Cultured rat olfactory neurons are excitable and respond to odors. Dev Brain Res 53:125-130.

Pyatkina GA (1982) Development of the olfactory epithelium in man. Z Mikrosk Anat Forsch Leipzig 96:361-372.

Rochel S, Margolis FL (1982) Carnosine release from olfactory bulb synaptosomes is calcium-dependent and depolarization-stimulated. $\mathrm{J}$ Neurochem 38:1505-1514.
Ronnett GV, Hester LD, Snyder SH (1991) Primary culture of neonatal rat olfactory neurons. J Neurosci 11:1243-1255.

Ronnett GV, Cho H, Hester LD, Wood SF, Snyder SH (1993) Odorants differentially enhance phosphoinositide turnover and adenylyl cyclase in olfactory receptor neuronal cultures. J Neurosci 13:1751-1758.

Schachner M, Antonicek H, Fahrig T, Faissner A, Fischer G, Kunemund V, Martini R, Mcyer A, Persohn E, Pollerberg E; Probstmeieir R, Sadoul K, Sadoul R, Seilheimer B, Thor G (1990) Families of neuronal cell adhesion molecules. In: Morphoregulatory molecules (Edelman GM, Cunningham BA, Thiery J-P, eds), pp 443-468. New York: Wiley.

Schmechel D, Marangos PJ, Brightman M (1978) Neuron-specific enolase is a molecular marker for peripheral and central neuroendocrine cells. Nature 276:834-836.

Schubert D, Stallcup W, LaCorbiere M, Kidokoro Y, Orgel L (1985) Ontogeny of electrically excitable cells in cultured olfactory epithelium. Proc Natl Acad Sci USA 82:7782-7786.

Schwartz Levey M, Chikaraishi DM, Kauer JS (1991) Characterization of potential precursor populations in the mouse olfactory epithelium using immunocytochemistry and autoradiography. J Neurosci 11: 3556-3564.

Schwob JE, Farber NB, Gottlieb DI (1986) Neurons of the olfactory epithelium in adult rats contain vimentin. J Neurosci 6:208-217.

Scott D, Smith KE, O'Bricn BJ, Angelides KJ (1985) Characterization of mammalian neurofilament triplet proteins: subunit stoichiometry and morphology of native and reconstituted filaments. J Biol Chem 260:10736-10747.

Shaw G, Weber K (1982) Differential expression of neurofilament triplet proteins in brain development. Nature 298:277-279.

Shirley SG, Robinson CJ, Dickinson K, Aujla R, Dodd GH (1986) Olfactory adenylate cyclase of the rat. Biochem J 240:605-607.

Sklar PB, Anholt RH, Snyder SH (1986) The odorant-sensitive adenylate cyclase of olfactory receptor cells: different stimulation by distinct classes of odorants. J Biol Chem 261:15538-15543.

Stagaard M, Mollgard K (1989) The developing neuroepithelium in human embryonic and fetal brain studied with vimentin-immunocytochemistry. Anat Embryol 180:17-28.

Steinert PM, Jones ICR, Goldman RD (1984) Intermediate filaments. J Cell Biol 99:22s-27s.

Sunshine J, Balak K, Rutishauser U, Jacobson M (1987) Changes in neural cell adhesion molecule (N-CAM) structure during vertebrate neural development. Proc Natl Acad Sci USA 84:5986-5990.

Takahashi S, Iwanaga T, Takahashi Y, Fujita T (1984) Neuron-specific encolase, neurofilament protein and S-100 protein in the olfactory mucosa of human fetuses. An immunohistochemical study. Cell Tissue Res 238:231-234.

Wang MM, Reed RR(1993) Molecular cloning of the olfactory neuronal transcription factor olf-1 by genetic selection in yeast. Nature 364:121-126.

Wolozin B, Sunderland T, Zheng B, Resau J, Dufy B, Barker J, Swerdlow $\mathrm{R}$, Coon H (1992) Continuous culture of neuronal cells from adult human olfactory epithelium. J Mol Neurosci 3:137-146.

Zigman JM, Westermank GT, LaMendola J, Boel E, Steiner DE (1993) Human $G_{\text {oll }}$ alpha: complementary deoxyribonucleic acid structure and expression in pancreatic islets and other tissue outside the olfactory neuroepithelium and central nervous system. Endocrinology 133:2508-2514. 